\title{
Relación entre el desempeño del docente de matemáticas y el rendimiento académico: caso de estudio de un colegio militarizado
}

\author{
Relationship Between Math Teacher Performance and Academic \\ Performance: Case Study of a Militarized College
}

Relação entre desempenho do professor de matemática e desempenho acadêmico: estudo de caso de uma escola militarizada

David Fernando Lozano Treviño

Universidad Autónoma de Nuevo León, México / Colegio de Bachilleres Militarizado "General Mariano Escobedo" del Estado de Nuevo León, México davidflozano@gmail.com http://orcid.org/0000-0002-5455-4223

Lauro Maldonado Maldonado

Universidad Autónoma de Nuevo León, México / Colegio de Bachilleres Militarizado "General Mariano Escobedo" del Estado de Nuevo León, México lamaldon@hotmail.com http://orcid.org/0000-0002-5071-0348 


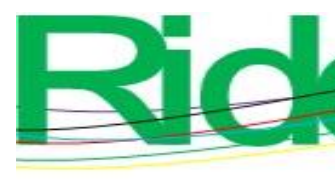

Revista Iberoamericana para la Investigación y el Desarrollo Educativo ISSN $2007-7467$

\section{Resumen}

El objetivo de la presente investigación fue señalar la asociación que existe entre el constructo "Desempeño docente de matemáticas" y la variable "Rendimiento académico en matemáticas" con el factor "Aspectos positivos del estudiante", caracterizado por la perseverancia, la resiliencia y el reconocimiento de la disciplina, en el Colegio de Bachilleres Militarizado General Mariano Escobedo del Estado de Nuevo León. El estudio fue transversal, no experimental, descriptivo y correlacional, con una prueba estandarizada aplicada de manera censal a 484 alumnos de cuarto, quinto y sexto semestre de los planteles Apodaca, San Bernabé y San Nicolás. Se corrió una técnica de regresión lineal múltiple entre el constructo y la variable exógenos y el factor latente. Se propuso un modelo teórico que refleja las variables comprendidas en los factores y un modelo empírico que muestra la relación entre estos. Los resultados arrojaron que existe asociación del trabajo que los profesores de matemáticas llevan a cabo en el aula y las calificaciones de los alumnos en esta materia con ciertas características personales de los bachilleres como la perseverancia, la resiliencia y el reconocimiento de la disciplina. En conclusión, se sugiere el uso de ejercicios y tareas en matemáticas que ayuden a memorizar conceptos y procedimientos, así como a aplicar los conocimientos adquiridos en clase a problemas o situaciones, para estimular así los aspectos positivos de los estudiantes.

Palabras clave: disciplina, docente de matemáticas, perseverancia, rendimiento académico, resiliencia.

\section{Abstract}

The purpose of this investigation was to point out the association between the construct "Math teaching performance" and the variable "Math academic performance" with the factor "Student positive aspects", characterized by perseverance, resilience and recognition of discipline, in the Colegio de Bachilleres Militarizado General Mariano Escobedo del Estado de Nuevo León. The study was cross-sectional, non-experimental, descriptive and correlational, with a standardized test census applied to 484 fourth, fifth and sixth grade students from Apodaca, San Bernabé and San Nicolás units. A multiple linear regression technique was run with the independents construct and variable and the dependent factor. A theoretical model that reflects the variables included in the factors was proposed. The results showed that there is an association between the work that the math teacher carries out in the 


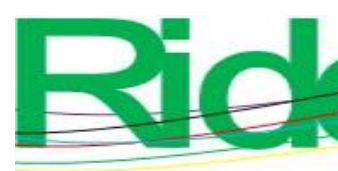
Revista Iberoamericana para la
Investigación y el Desarrollo Educativo
ISSN $2007-7467$

classroom and the levels of certain students' personal characteristics such as perseverance, resilience and discipline recognition. Therefore, an empirical model is exposed. In conclusion, the use of exercises and tasks in math that help students to memorize concepts and procedures as well as apply the knowledge acquired in class to solved problems or situations is suggested to stimulate study positive personal aspects.

Keywords: discipline, math teacher, perseverance, academic achievement, resilience.

\section{Resumo}

O objetivo desta pesquisa foi apontar a associação que existe entre o construto "Desempenho no ensino de matemática" e a variável "Desempenho acadêmico em matemática" com o fator "Aspectos positivos do aluno", caracterizado pela perseverança, resiliência e reconhecimento dos disciplina, no Colégio Militar General Mariano Escobedo do Estado de Nuevo León. O estudo foi transversal, não experimental, descritivo e correlacional, com teste padronizado aplicado de forma censitária a 484 alunos do quarto, quinto e sexto semestres das escolas Apodaca, San Bernabé e San Nicolás. Uma técnica de regressão linear múltipla foi executada entre a variável exógena e o construto e o fator latente. Foi proposto um modelo teórico que reflete as variáveis incluídas nos fatores e um modelo empírico que mostra a relação entre eles. Os resultados mostraram que existe uma associação entre o trabalho que os professores de matemática realizam em sala de aula e as notas dos alunos dessa disciplina com determinadas características pessoais dos egressos do ensino médio como perseverança, resiliência e reconhecimento da disciplina. Em conclusão, sugere-se a utilização de exercícios e tarefas de matemática que ajudem a memorizar conceitos e procedimentos, bem como a aplicar os conhecimentos adquiridos nas aulas a problemas ou situações, de forma a estimular os aspectos positivos dos alunos.

Palavras-chave: disciplina, professor de matemática, perseverança, desempenho acadêmico, resiliência.

Fecha Recepción: Abril 2021

Fecha Aceptación: Octubre 2021 


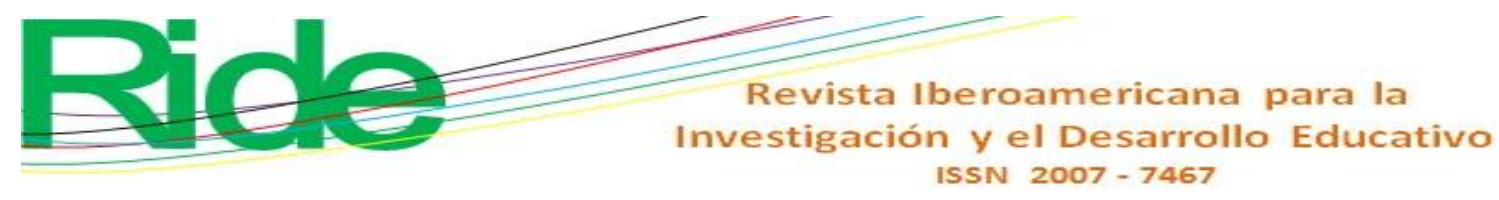

\section{Introducción}

Si bien en la educación media superior (EMS) la principal misión es que los jóvenes adquieran competencias para insertarse en un puesto laboral o continuar sus estudios superiores, también está el objetivo de que desarrollen características o aspectos personales necesarios para vivir en comunidad y enfrentar la vida adulta (Landero, 2012, p. 18). Para medir el logro de dicho propósito se requiere determinar tanto los conocimientos, habilidades y valores como las actitudes y singularidades necesarios para la competitividad de la persona (Martínez, Guevara y Valles, 2016, p. 124). El resultado esperado, allende de acreditar el nivel, será la formación de un ciudadano listo para convivir asertivamente en su entorno empleando, y a su vez enriqueciendo, aquellas competencias adquiridas, incluyendo ciertos aspectos personales desarrollados durante su permanencia en la preparatoria (Carlos, 2016, p. 288; Jaik y Barraza, 2011, p. 222).

En consecuencia, las instituciones educativas están obligadas a planear e implementar estrategias pedagógicas para lograr tal fin (Peña y Vera, 2014, p. 251; Sesento y Lucio, 2017, p. 34; Silas, 2008, p. 3; Smitter, 2008, p. 2). El aprendizaje de los jóvenes y aquellas particularidades individuales provechosas engloban comprender información, emplear el conocimiento, adaptarse al entorno cambiante (Salazar, Peña y Medina, 2018, p. 38) y comportarse bajo normas establecidas y apropiadas (Fernández, 2014, p. 2). Sin embargo, los adolescentes arriban al bachillerato con deficiencias tanto en sus destrezas cognitivas como socioemocionales (Tuirán, 2017, p. 13). Como sea que fuere, lo relevante es que desarrollen estas durante su estancia preparatoriana, donde el actuar escolar diario estimule el conocimiento e incida en la confianza, motivación (Gómez, 2010, p. 232), participación social efectiva y en las conductas positivas de los jóvenes (Encinas, Peralta, Cuevas y Anseldo, 2017, p. 2).

Por lo que se refiere a los docentes, específicamente los de matemáticas, su desempeño es pieza clave para lograr los propósitos trazados en la EMS. Realizan sus labores compartiendo experiencias y aplicando ejercicios y tareas con la finalidad de que los alumnos materialicen las lecciones esperadas (Tello y Tello, 2013, p. 89) y perfeccionen sus aptitudes (Rodríguez, 2011, p. 1) y actitudes (Carlos, 2016, p. 288). Los modelos educativos actuales

invitan a una enseñanza de las matemáticas activa y versátil con actores decididos y comprometidos (Salazar et al., 2018, p. 54). En esa línea, los docentes deben propiciar el aprendizaje, dominar la materia y entender las diferentes maneras en las que los alumnos 


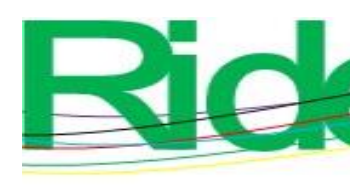

Revista Iberoamericana para la Investigación y el Desarrollo Educativo ISSN 2007 - 7467

captan los contenidos (Martínez, 2018), sin olvidar que estos últimos deben dirigir su propia enseñanza y sus conductas. Así, conquistar las metas de la EMS es responsabilidad de todos los actores que participan en el contexto escolar.

Por último, dentro de los retos que tiene la EMS se encuentra el bajo rendimiento académico en matemáticas (Rodríguez, 2011, p. 1), así como deficiencias en la formación humana, principalmente en el manejo de emociones, creación de hábitos de estudio, liderazgo y valores (Gómez y Vázquez, 2014, p. 3). Pruebas como el Plan Nacional para la Evaluación de los Aprendizajes (Planea) tienen el propósito de conocer el estado de la adquisición de conocimientos claves en los campos de habilidades numéricas y lingüísticas (Instituto Nacional para la Evaluación de la Educación [INEE], 2017, p. 2). Sin duda, los resultados en este tipo de evaluaciones se dan tanto por factores internos como externos, incluyendo en los primeros aspectos personales de los alumnos (Gaxiola, González y Contreras, 2011, p. 166). Los estudiantes que salen bien calificados tienen el potencial de mayor prosperidad gracias a que afinan sus conocimientos y estos, a su vez, amplifican aquellos comportamientos personales que los inducen al éxito.

Para los propósitos de este estudio, el desempeño del docente de matemáticas comprende la aplicación de ejercicios y tareas que ayuden a memorizar y aplicar los conceptos, procedimientos y conocimientos adquiridos. Luego, el rendimiento académico en matemáticas es el resultado de la prueba diagnóstica estandarizada tipo Planea aplicada por el Consejo Nuevo León para la Planeación Estratégica y que mide las habilidades numéricas de los alumnos. Finalmente, los elementos determinantes para los aspectos positivos de los estudiantes incluyen la perseverancia, la resiliencia y el reconocimiento de la disciplina, este último por ser una propiedad de importancia en instituciones educativas militarizadas, donde se llevó a cabo el presente trabajo.

Por lo anterior, la pregunta de investigación es: ¿de qué manera se asocian el desempeño de los docentes de matemáticas y los resultados de las evaluaciones en esta materia con características personales de los alumnos como la perseverancia, resiliencia y la confianza en el líder? El objetivo fue asociar el constructo y la variable exógenas conceptualizados como "Desempeño docente de matemáticas" y "Rendimiento académico en matemáticas", respectivamente, con el factor "Aspectos positivos del estudiante". La hipótesis propuesta fue que a mayor desempeño docente de matemáticas y mayor rendimiento académico en matemáticas mayor desarrollo de aspectos positivos del estudiante. 


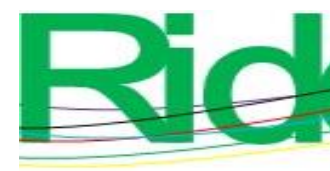

Revista Iberoamericana para la Investigación y el Desarrollo Educativo

ISSN 2007 - 7467

El presente artículo está dividido en cuatro partes. Primero, se detalla un marco teórico sobre las estrategias y herramientas didácticas empleadas por los docentes de matemáticas, los resultados obtenidos en las evaluaciones de esta unidad de aprendizaje y la perseverancia, la resiliencia y el reconocimiento de la disciplina como aspectos positivos de los estudiantes de EMS. Segundo, se describe el contexto donde se realizó el estudio, así como la metodología de la investigación, los instrumentos, pruebas estandarizadas y las bases de datos empleados. Luego, se detallan los resultados y se discuten los modelos teóricos y empíricos propuestos. Finalmente, se concluye, se desvelan futuras líneas de investigación y se proponen recomendaciones para los docentes de matemáticas y directores de EMS que contribuyan a formar aspectos, o características, positivos en los bachilleres.

\section{Marco teórico}

\section{Desempeño del docente de matemáticas en la EMS}

El rendimiento académico de los estudiantes está en función directa con el accionar docente en el aula (Lara, Aguilar, Cerpa y Núñez, 2009, p. 1; Padilla y Villafuerte, 2018, p. 15), quien estimula el desarrollo de habilidades cognitivas y socioemocionales en el alumno (Tuirán, 2017, p. 14). Originar una mejor comprensión de entes abstractos, favorecer el razonamiento lógico y propiciar emociones positivas hacia los números y las figuras geométricas en general es una de las principales tareas de los profesores de matemáticas (Gómez, 2010, p. 228).

Los maestros competitivos, incluidos los de matemáticas, favorecen el autoconocimiento de los estudiantes, inyectan en ellos deseos de superación y expectativas para su crecimiento académico, profesional y humano, orientan las sanas prácticas sociales (Secretaría de Educación Pública [SEP], 29 de octubre de 2008), cuentan con habilidades para la enseñanza, así como dominio de los planes y programas de estudio (Dolores y García, 2016, p. 72), emplean diversos materiales didácticos (SEP, 2015, p. 8) y apoyan a los alumnos en todo momento (Santana, Marchena, Martín y Alemán, 2018, p. 367).

Los objetivos a alcanzar en las matemáticas se relacionan con que los alumnos sean capaces de llevar a cabo operaciones numéricas, identificar sus jerarquías, manejar el lenguaje del álgebra, usar ecuaciones lineales, entre otros, que les permita resolver retos y situaciones de la vida diaria (SEP, 2019, p. 6); también, estimar comportamiento de variables, 


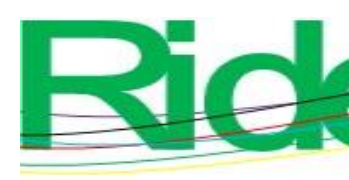

Revista Iberoamericana para la
Investigación y el Desarrollo Educativo
ISSN $2007-7467$

interpretar símbolos matemáticos y experimentar las dimensiones del espacio y las características físicas de los objetos (Martínez y Camarena, 2015, p. 194).

Aquellos profesores de matemáticas que buscan la calidad en su quehacer profesional están en preparación continua, construyen ambientes de enseñanza adecuada, planifican el curso y sus clases diarias, llevan los conocimientos del aula a la vida diaria, buscan conocer y satisfacer las necesidades académicas, y en ocasiones las de índole personal, de los alumnos; son ejemplo de disciplina, perseverancia y superación (Martínez et al., 2016, p. 127); articulan contenidos previos y entre materias, cuentan con basto material didáctico y aplican diversas herramientas de evaluación; invitan a la participación y construcción de conocimiento en conjunto, otorgan recompensas y motivan a levantarse de los fracasos académicos (Tello y Tello, 2013, p. 89); promueven el interés por las matemáticas y son capaces de compartir sus experiencias en este campo (Artavia, 2005, p. 3; Covarrubias y Piña, 2004, p. 64); emplean estrategias para que la enseñanza de las matemáticas sea accesible para todos (Carlos, 2016, p. 305), se adaptan a las diferentes características conductuales y cognitivas de los jóvenes, así como de sus entornos socioculturales (Camberos, Lechuga y Salinas, 2014, p. 11), alinean los contenidos con las necesidades de los estudiantes, además de que son promotores de la convivencia (Grupo de trabajo "Investigación sobre el abandono escolar temprano", 2013, p. 13); plantean situaciones que generan conflicto de valores y estimulan la crítica y la creatividad con el objetivo de generar experiencias valiosas (Jaik y Barraza, 2011, p. 228); reflexionan sobre los problemas de la enseñanza de las matemáticas y proponen y aplican medidas de solución (Aké, Martínez y López, 2018, p. 129) y son flexibles en sus dinámicas (Rodríguez, 2011, p. 4).

Los docentes, en particular los de matemáticas, suelen representar un reto académico positivo para los bachilleres, pues despiertan el deseo de esfuerzo y perseverancia. También, son motivo de inspiración para levantarse de los fracasos matemáticos y seguir enfrentando el curso (Silas, 2008, p. 14), invitan a la construcción y aplicación del conocimiento sin miedo al error (Morales, 2017, p. 37), le dan mucha importancia a los logros y lo transmiten en el aula (Hernández y Ceniceros, 2018, p. 174), son paladines emocionales de sus estudiantes (Venet y Díaz, 2018, p. 5), incitan a incrementar tanto la voluntad como el autoaprendizaje y la autoregulación, aportan ideas y experiencias profesionales y personales que preparan a los jóvenes para la vida y sus contextos (Peña, Andrade y Aké, 2018, p. 99; Roux y Anzules, 2015, p. 3), son motor de motivación y desafío intelectual (Barojas y Ramírez, 2015, p. 71), son dedicados para sus alumnos y monitorean sus avances y si estos no se dan, se detienen 


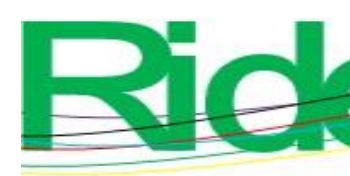

\section{Revista Iberoamericana para la Investigación y el Desarrollo Educativo ISSN 2007 - 7467}

para volver a explicarles (Morales, 2018, p. 80), fomentan hábitos de estudio para que sean implementados en clase, en la casa y más allá del aula (Sesento y Lucio, 2017, p. 32), despiertan el interés por el estudio (López, García y Díaz, 2018, p. 92), tornan simple lo complejo, propician espacios agradables, apoyan y empatizan con los alumnos y anteponen la formación de estos (Vidal y Márquez, 2016, p. 103), invitan a la participación (Cerda, Salazar, Guzmán y Narváez, 2018, p. 265), son accesibles tanto en clase como fuera de ella (Basto, 2017, p. 2), tienen mucha disponibilidad y son claros en las instrucciones académicas que giran (Barragán, Aguilar, Cerpa y Núñez, 2009, p. 4), así como en los consejos que comparten (Covarrubias y Piña, 2004, p. 64).

Por otra parte, factores relacionados con el afecto docente-alumno, tal y como las actitudes y emociones, están asociados a un mayor rendimiento académico en matemáticas, mientras que menores promedios en dicha unidad de aprendizaje desmotivan a los alumnos (Escobar, 2015, p. 6; García, 2009, p. 6; Hernández, Rivera y Garza, 2017, p. 7), generan ganas de desertar y disminuyen sus expectativas en la vida (Becerra y Reidl, 2015, p. 82; Ricoy y Couto, 2018, p. 70). Más allá de las habilidades numéricas, el quehacer del docente en el aula favorece la práctica de la tolerancia, temple, discernimiento, estabilidad y dominio de las emociones mediante la práctica de la matemática (Rivera, Figueroa y Edel, 2013, p. 31), los alumnos de bachillerato suelen estar de acuerdo con que sus maestros de matemáticas los presionen para obtener mejores resultados (Tapia, Tamez y Tovar, 1994, p. 116) e impriman mayor esfuerzo (Barrales, Gómez y Guerrero, 2015, p. 884).

El entendimiento y la correcta aplicación de las matemáticas impulsa la vida productiva de las sociedades, es pieza clave en la innovación y desarrollo tecnológico, además de que les brinda a las personas mayores posibilidades de éxito, pues contribuyen a formar un individuo edificante, responsable y reflexivo (Martínez et al., 2017, p. 43). El manejo de las matemáticas estimula el trabajo en equipo, promueve la costumbre de ser evaluado (Martínez y Camarena, 2015, p. 192), la formación continua y coadyuva al desarrollo de conductas como la perseverancia y resiliencia (Tuirán y Hernández, 1 de noviembre de 2015, p. 8), así como la cultura general (Lara et al., 2009, p. 11) y construye hábitos de supervivencia académica que se trasladan a actividades extraclase y al ámbito laboral.

Así, para la presente investigación el desempeño docente de matemáticas se define como el ejercicio del profesor que imparte esta unidad de aprendizaje y que, mediante la 


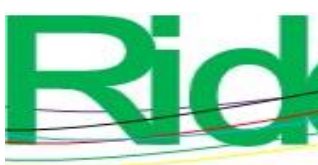

Revista Iberoamericana para la Investigación y el Desarrollo Educativo ISSN 2007 - 7467

cátedra y la aplicación de tareas y ejercicios, incide en los alumnos para que apliquen los conocimientos y resuelvan diversos problemas o situaciones.

\section{El rendimiento académico en matemáticas en la EMS}

El rendimiento académico es la consecuencia de lo aprendido según la valoración realizada por el profesor mediante exámenes, tareas, trabajos grupales y otras actividades como la asistencia a clases (Chilca, 2017, p. 18; Saucedo, Herrera, Díaz, Bautista y Salinas, 2014, p. 88); se refiere a la certificación de las competencias de aquellos alumnos que concluyeron satisfactoriamente sus estudios; es el proceso de adquirir conocimientos, habilidades, actitudes y valores para adaptarse e interactuar con el entorno (Becerra y Reidl, 2015, p. 81); ubica la eficacia, la autorregulación académica del estudiante y el trabajo del docente y se expresa mediante el promedio o las calificaciones (Roux y Anzures, 2015, p. 4); mide lo aprendido y las destrezas con los que se debe contar al llegar a la adultez (SEP, 26 de septiembre de 2018, p. 10); incluye la cuantificación de sus aspiraciones e intereses (Saucedo et al., 2014, p. 6). En lo que respecta a la unidad de aprendizaje matemáticas, el rendimiento se refiere a la capacidad del alumno de solventar problemas de la vida real aplicando el conocimiento matemático; el estudiante desarrolla habilidades como elaborar problemas numéricos, aplicar proporcionalidades, el uso del lenguaje algebraico, obtener productos de expresiones, el cálculo del perímetro y áreas de figuras, entre otros (SEP, 2019, p. 2). El rendimiento académico es el indicador más empleado para identificar el conocimiento de los bachilleres, así como sus esfuerzos y capacidades en esta disciplina (Gaxiola et al., 2011, p. 53).

La medición de los conocimientos y habilidades matemáticas en los jóvenes de EMS ha sido una preocupación desde hace años en todo el mundo. Las pruebas estandarizadas reproducen lo comprendido en los contenidos escolares y revisan si los estudiantes son capaces de aplicar lo aprendido en diversas circunstancias de la vida como individuo comprometido y reflexivo (Martínez et al., 2017, p. 7). Las evaluaciones matemáticas, las cuales son las de mayor reprobación (Vidales, 2009, p. 329), tienen por objeto identificar el pensamiento matemático, las destrezas para solucionar problemas, las actitudes hacia los números, los valores adquiridos (Flores y Gómez, 2009, p. 123) y los desafíos que se tengan para aprender, que no necesariamente tienen que ver con factores cognitivos o pedagógicos. En la aplicación de evaluaciones de esta asignatura, se recomienda la participación de 


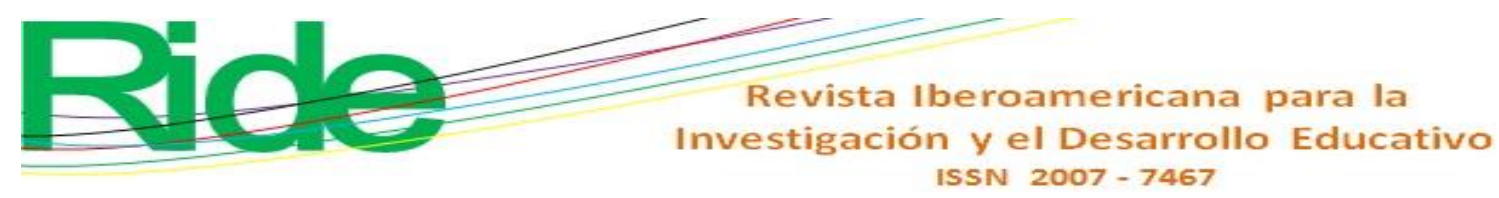

estudiantes, docentes, padres de familia y personal administrativo (Dolores y García, 2016, p. 34).

Los alumnos con suficiente rendimiento académico en matemáticas han desarrollado hábitos de estudio (Sesento y Lucio, 2017, p. 32), sus propias estrategias de aprendizaje, actitudes positivas hacia el conocimiento (Padilla y Villafuerte, 2018, p. 18), mayores aspiraciones, su personalidad (Martínez-Otero, 2009, p. 17), su madurez, responsabilidad para enfrentar los problemas personales (Dzay y Narváez, 2012, p. 29), su motivación (Sánchez, Téllez, Sánchez y Reyes, 2017, p. 3), ambiciones (Ortega, Macías y Hernández, 2014, p. 35), la capacidad para hacer frente a los retos de la vida, su grado de adaptabilidad (Corzo, 2016, p. 10), su afectividad y perseverancia (Ricoy y Couto, 2018, p. 74).

Instrumentos como el Programa para la Evaluación Internacional de los Estudiantes (PISA) ubican las competencias de los estudiantes para aplicar en la vida práctica lo aprendido en esta disciplina (Barojas y Ramírez, 2015, p. 72). También, sitúan características socioemocionales como persistencia, manejo de estrés, empatía y toma de decisiones (Hernández y Backhoff, 2017, p. 25). Determina el estado del alumnado de EMS en el uso e interpretación numéricos, pensamiento algebraico y manejo de espacios, formas, medidas e información. Las calificaciones obtenidas se pueden posicionar en cuatro niveles: en el primero, los estudiantes tienen retos para efectuar operaciones con fracciones o variables; en el segundo, realizan cálculos con porcentajes; en el tercero, la aplicación del lenguaje de las matemáticas les permite hacer problemas con incógnitas; y en el cuarto, los alumnos solucionan problemas de contenidos matemáticos vistos hasta el último grado del bachillerato. En México, $66.2 \%$ de los estudiantes no logra superar el nivel I y $23.3 \%$ llega hasta el nivel II (INEE, 2017, p. 6).

Dentro de los desafíos que tiene la evaluación de las matemáticas se encuentran el cambio de la cultura del aprendizaje, enseñar no solo para las evaluaciones sino para resolver conflictos personales y profesionales, múltiples objetivos fijados en el aprendizaje que han desviado la focalización de propósitos principales de la preparación para la vida, las formas de calificar que no están alineadas a principios pedagógicos y las aplicaciones de exámenes individuales cuando en la práctica se cuenta con posibilidades de trabajar en equipo y emplear las tecnologías de la información (Santiago, McGregor, Nusche, Ravelo y Toledo, 2012, p. 133). Además, la valoración del alumno debe arrojar datos que permitan normalizar el nivel real de conocimientos y así diseñar ambientes adecuados según los niveles y edades, motivar la creatividad, asociar el impacto que el aprendizaje tiene en las capacidades intelectuales y 


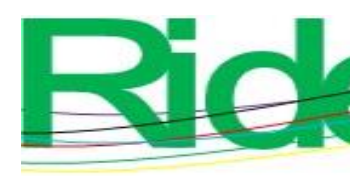

\section{Revista Iberoamericana para la Investigación y el Desarrollo Educativo ISSN 2007 - 7467}

socioemocionales de los muchachos, erradicar el temor al fracaso, vincular el aprendizaje con las necesidades comunitarias y favorecer el autoaprendizaje.

Por lo tanto, el rendimiento académico en matemáticas es el resultado obtenido en las habilidades numéricas de la prueba estandarizada tipo Planea aplicada por el Consejo Nuevo León para la Planeación Estratégica y que refleja las competencias matemáticas de los alumnos del Colegio de Bachilleres Militarizado General Mariano Escobedo del Estado de Nuevo León (CBMNL).

\section{Aspectos positivos de los estudiantes de EMS}

La misión de la EMS es transmitir conocimientos, así como perfeccionar la personalidad de los estudiantes (Sesento y Lucio, 2017, p. 34). Los modelos educativos actuales ponen en el centro a los alumnos para que ellos mismos sean los protagonistas en el desarrollo de aprendizajes y habilidades socioemocionales (Salazar et al., 2018, p. 69). Además, favorecen la evolución de valores y actitudes positivas, así como la innovación, permanencia y elasticidad académica (El Sahili, 2011, p. 36); promueven el establecimiento de planes de trayectoria personal y profesional, la asertividad, el liderazgo (Gómez y Vázquez, 2014, p. 3) e invitan a que las escuelas sean un espacio para fortalecer la seguridad sensitiva, acrecentar la confianza (Castro y Morales, 2015, p. 13), despertar la adaptabilidad (Campos, Castaño y Valencia, 2013, p. 44) y el dominio y desarrollo de las emociones (Escobar, 2015, p. 67; Rivera et al., 2013, p. 123).

Existe una correlación entre el razonamiento matemático y la intensidad de ciertas cualidades personales como el estado de ánimo, compromiso, satisfacción, resiliencia, perseverancia, disciplina (Gómez, 2010, p. 229), responsabilidad, grado de ajuste al entorno y capacidad para adquirir y emplear estrategias cognitivas (Salazar et al., 2018, p. 41). Las características personales son conductas con respecto a actividades a desarrollar y valores sociales que inciden en la convivencia (Flores y Gómez, 2009, p. 127); es la formación socioemocional que determinará la toma de decisiones y la manera en que se enfrentarán los retos individuales (Hernández y Backhoff, 2017, p. 25). El rendimiento académico incide en los aspectos de los alumnos mencionados (Corzo, 2016, p. 100; Landero, 2012, p. 7; Tuirán y Hernández, 1 de noviembre de 2015), incluido el desempeño en matemáticas (Ricoy y Couto, 2018, p. 70), por lo que la resiliencia, la perseverancia y la falta de asertividad en el liderazgo son afectadas (Salvà, Oliver y Comas, 2014, p. 73). 


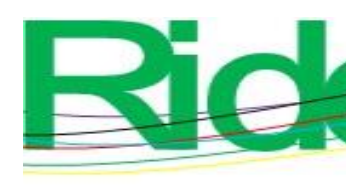

Revista Iberoamericana para la Investigación y el Desarrollo Educativo ISSN 2007 - 7467

Primero, la resiliencia, en el contexto académico, es la superación de los riesgos, sacar provecho intelectual de ellos y buscar tornarlos en aspectos positivos (Gaxiola et al., 2011, p. 165); es la recuperación emocional frente a las desventuras escolares que provocan enojo o estrés (Alonso, Beltrán, Méfara y Gaytán, 2016, p. 42); es el ajuste emocional del alumno frente a situaciones inquietantes o desfavorables y en donde la ilustración es determinante para su buen manejo (Campuzano y Libien, 2019, p. 2); refiere a las habilidades del estudiante que se encuentra en algún tipo de vulnerabilidad social para enfrentar infortunios (García y Klein, 2014, p. 11; Lagos y Osse, 2010, p. 38). Incluye el dominio de actitudes (Monroy, Jiménez, Ortega y Chávez, 2013), salir fortalecido con altas expectativas, lo que provoca un círculo virtuoso porque disminuye la reprobación y el abandono escolar (Silas, 2008, p. 4), y las maneras de reaccionar a las adversidades y a las experiencias desagradables (Arguedas y Jiménez, 2007, p. 11). La resiliencia es pieza clave para obtener el éxito académico (Ruiz, 2013, p. 118; Smulders, 2018, p. 132;) e incide en la eficiencia del desempeño escolar (Hernández y Ceniceros, 2018, p. 174). En el otro extremo, las desventuras académicas incluyen excesos de tareas, estrictas evaluaciones, laboriosas actividades, poco tiempo disponible para las clases, el grado de dificultad de las materias y ambientes académicos desagradables (Barraza y Silerio, 2007, p. 49; Domínguez, Gutiérrez, Llontop, Villalobos y Delva, 2015, p. 36). Por lo que la resiliencia en el contexto académico, para el presente artículo, se conceptualiza como la reacción controlada del estudiante que permite superar obstáculos que pueden provocar sentimientos que afecten.

Después, la perseverancia en el entorno escolar es la dedicación hacia las tareas académicas (Silas, 2008, p. 4); la diferencia que percibe el estudiante del beneficio invertido en las tareas académicas y el costo de abandonar la escuela (Landero, 2012, p. 41); practicar hábitos de estudio (Chilca, 2017, p. 72); fijarse metas, trabajar por ellas (Poy, 2010, p. 161) y lograrlas (Lugo, 2013, p. 306); el interés, planificación, esfuerzo, empeño por la comprensión y dominio de los contenidos, sentir que se tiene el control del desempeño y contar con la motivación para adquirir mayor conocimiento (López et al., 2018, p. 92), pues se comprende que una vez conseguido el aprendizaje, ya sea contenido fácil o difícil, llevará a una vida mejor (Roux y Anzures, 2015, p. 2) y al óptimo rendimiento (Velázquez y González, 2017, p. 123). Por lo anterior, se considera a la perseverancia como el interés continuo por ideas o metas y que se demuestra afrontando los retos de la vida y superándolos.

Finalmente, el reconocimiento de la disciplina se puede conceptualizar como aceptar las instrucciones de lo que se debe hacer y ejecutarlo de manera autónoma mientras se 


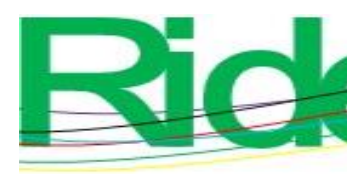

\section{Revista Iberoamericana para la Investigación y el Desarrollo Educativo ISSN 2007 - 7467}

controla y reflexiona su quehacer (Roux y Anzures, 2015, p. 2). El líder académico es un referente para los demás: puede ser el docente, algún estudiante o incluso padres de familia. Motiva a llegar a tiempo a clases, a ser propositivo, organizado, comprometido, incita a ser respetuoso, honesto y compartido (Mesa, Marcos y Vidales, 2017, p. 59), motiva al cambio de los estudiantes, los vuelve más competitivos y así contribuye a alcanzar las metas trazadas (Álvarez, Torres y Chaparro, 2016, p. 165), fija objetivos, tiende a influir para que las expectativas sean elevadas y se compromete a generar climas ordenados y cooperativos (Robinsen, Lloyd y Rowe, 2014, p. 13), guía a los estudiantes hacia la mejora de la calidad a través del desarrollo de aspectos positivos de sus personas y la innovación (Sierra, 2016, p. 115), mediante relaciones empáticas y asertivas hacen saber a los miembros del equipo que son importantes y que por sus acciones generan valor a la escuela (Reyes, Trejo y Topete, 2017, p. 4) y abre el diálogo en clase, favorece la participación e invita a los estudiantes a la reflexión (Zapata, 2017, p. 88). Así, el reconocimiento de la disciplina es aceptar la guía de algún integrante del entorno escolar mediante la comunicación constante.

\section{Método}

\section{Contexto del estudio}

El CBMNL es una institución pública estatal de EMS que inició operaciones en febrero de 2017. Combina el modelo académico por competencias empleado en las escuelas civiles con disciplina militar. Cuenta con una matrícula de 2171 alumnos en cuatro planteles (GNL, 2019, p. 195), con $40 \%$ del género femenino y $60 \%$ del masculino, que acuden a clase de lunes a viernes de 7:00 horas a 18:00 horas. Además de sus clases de bachillerato, los jóvenes reciben tres horas diarias de educación física e instrucción militarizada y se capacitan para el trabajo como Instructores de educación física y auxiliares contables de almacén (CBMNL, 2019, p. 14).

Por otro lado, el Consejo Nuevo León para la Planeación Estratégica (CONL) fue formado en el año de 2014 como un órgano transexenal con base en la Ley de Planeación Estratégica del Estado de Nuevo León. Su propósito es favorecer el desarrollo sustentable de la entidad, así como el bienestar de todas las personas que habitan en el estado. Para ello, se establecen planes y objetivos a largo plazo que coadyuven a la planeación y evaluación de las políticas públicas. Está conformado por miembros de los tres poderes del Estado, la delegada estatal de Programas para el Desarrollo en Nuevo León, empresarios 

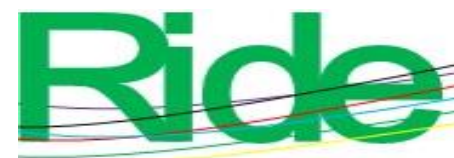

Revista Iberoamericana para la Investigación y el Desarrollo Educativo

ISSN 2007 - 7467

nuevoleoneses, los rectores del Tecnológico de Monterrey, la Universidad Autónoma de Nuevo León y la Universidad de Monterrey, así como expertos en desarrollo humano, transparencia, desarrollo sustentable, desarrollo económico, seguridad y justicia (CONL, 2020a).

En noviembre de 2019, el CONL evaluó el programa presupuestal CBMNL aplicando una prueba estandarizada tipo Planea para 484 alumnos de cuarto, quinto y sexto semestre de los planteles de Apodaca, San Bernabé y San Nicolás. Su objetivo fue ubicar las habilidades matemáticas y de lenguaje y comunicación entre los estudiantes. Adicionalmente, obtuvo información sobre el contexto y las habilidades socioemocionales mediante un cuestionario que fue contestado por los alumnos (CONL, 2020b, p. 32).

\section{Metodología de la investigación}

El presente estudio es transversal, no experimental, descriptivo y correlacional. Se utilizó la Evaluación Integral para los Planteles del Colegio de Bachilleres Militarizado de Nuevo León del CONL (2020b) como base de datos. Los datos se procesaron en el software SPSS 22.

Los aspectos positivos del estudiante fueron considerados como un factor latente y este se midió con base en las respuestas del cuestionario de contexto y socioemocional. Asimismo, se constituyeron dos factores y una variable para conformar el modelo teórico propuesto en la tabla 1, mientras que en la figura 1 se plasman los constructos y la descripción de las variables que los conforman.

En relación con la construcción de los factores, "Desempeño docente de matemáticas" y "Aspectos positivos del estudiante", la técnica utilizada fue mediante estadísticas de fiabilidad, alfa de Cronbach $(\alpha)$. Se consideró significativo un resultado estadístico mayor o igual a 0.7 (George y Mallery, 2003, p. 188), por lo que las variables miden un mismo constructo y están relacionadas (Welch y Comer, 1988, p. 83). Para considerar que los resultados fueron estadísticamente significativos se estableció un p-valor menor a 0.05. Igualmente, se aplicó el criterio de extracción de las variables con productos menores. 


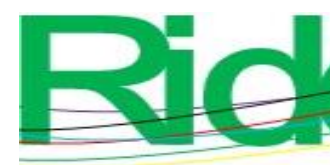

Revista Iberoamericana para la Investigación y el Desarrollo Educativo

ISSN 2007 - 7467

Tabla 1. Modelo teórico conceptual

\begin{tabular}{|c|c|c|}
\hline Constructo & Variable & Pregunta en la encuesta o calificación \\
\hline \multirow[t]{2}{*}{$\begin{array}{c}\text { Desempeño docente } \\
\text { de matemáticas }\end{array}$} & DDM1 & $\begin{array}{l}\text { Los maestros de matemáticas dejan ejercicios y } \\
\text { tareas que ayudan a memorizar conceptos y } \\
\text { procedimientos. }\end{array}$ \\
\hline & DDM2 & $\begin{array}{l}\text { Los maestros de matemáticas dejan ejercicios y } \\
\text { tareas que ayudan a aplicar los conocimientos } \\
\text { adquiridos en clase a problemas o situaciones. }\end{array}$ \\
\hline $\begin{array}{l}\text { Rendimiento } \\
\text { académico en } \\
\text { matemáticas }\end{array}$ & RAM & $\begin{array}{l}\text { Resultado en matemáticas de la prueba } \\
\text { estandarizada tipo Planea aplicada por el CONL. }\end{array}$ \\
\hline \multirow[t]{8}{*}{$\begin{array}{l}\text { Aspectos positivos } \\
\text { del estudiante }\end{array}$} & APE1 & $\begin{array}{l}\text { Alguna vez me obsesioné con una idea o meta } \\
\text { por un tiempo corto, pero más tarde perdí el } \\
\text { interés. }\end{array}$ \\
\hline & APE2 & $\begin{array}{l}\text { Tengo dificultad para mantener mi atención en } \\
\text { metas que requieren varios meses para ser } \\
\text { terminadas. }\end{array}$ \\
\hline & APE3 & $\begin{array}{l}\text { ¿Con qué frecuencia pensé que no podía afrontar } \\
\text { todas las cosas que tenía que hacer en el último } \\
\text { mes? }\end{array}$ \\
\hline & APE4 & $\begin{array}{l}\text { Soy una persona que se enoja cuando me ponen } \\
\text { obstáculos a lo que pretendo hacer. }\end{array}$ \\
\hline & APE5 & $\begin{array}{l}\text { ¿Con qué frecuencia me afectó algo que me } \\
\text { ocurrió inesperadamente en el último mes? }\end{array}$ \\
\hline & APE6 & $\begin{array}{l}\text { ¿Con qué frecuencia me enojé porque las cosas } \\
\text { que me ocurrieron estaban fuera de mi control en } \\
\text { el último mes? }\end{array}$ \\
\hline & APE7 & $\begin{array}{l}\text { Frecuentemente tengo conflictos con el líder de } \\
\text { mi grupo o de mi trabajo. }\end{array}$ \\
\hline & APE8 & $\begin{array}{l}\text { Tengo dificultades para comunicarme con mis } \\
\text { padres. }\end{array}$ \\
\hline
\end{tabular}

Fuente: Elaboración propia con base en el CONL (2020b) 

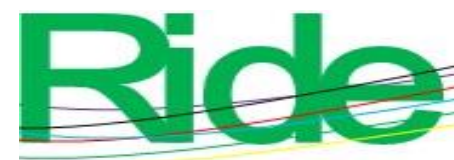

Revista Iberoamericana para la Investigación y el Desarrollo Educativo

ISSN 2007 - 7467

Además, con base en una extensa revisión bibliográfica, se propuso un modelo teórico conceptual (figura 1) en el cual asocia el constructo y la variable independientes y los aspectos positivos del estudiante. El factor independiente "Desempeño docente de matemáticas" se conformó de: a) la percepción del estudiante del grado de aplicación de ejercicios, por parte del docente de matemáticas, que ayudan a memorizar y $b$ ) la percepción del estudiante del grado de aplicación de ejercicios, por parte del docente de matemáticas, que ayudan a poner en práctica los conocimientos adquiridos a problemas o situaciones. Se obtuvo un $\alpha$ de 0.72 .

Para el factor dependiente, “Aspectos positivos del estudiante”, las variables incluidas fueron: $a$ ) interés por las metas, $b$ ) atención en las metas, $c$ ) afrontar las cosas, $d$ ) resiliencia ante obstáculos, e) resiliencia por sucesos inesperados, $f$ ) resiliencia por las cosas fuera de control, $g$ ) concordancia con el líder y $h$ ) comunicación con los padres. La fiabilidad expresada fue buena con 0.71 .

Finalmente, en cuanto a la variable "Rendimiento académico en matemáticas" se tomó el resultado de la habilidad numérica en la prueba estandarizada aplicada por el CONL en el CBMNL.

En el modelo teórico conceptual, los factores propuestos aparecen dentro de una elipsis por ser latentes, mientras que las variables situadas al interior de los rectángulos fueron medidas directamente (González y Treviño, 2018, p. 115). En el planteamiento del presente estudio se aprecia que tanto el factor como la variable se asocian directamente con los aspectos positivos de los estudiantes. 

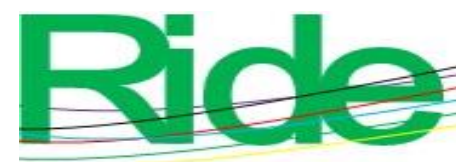

Figura 1. Modelo teórico conceptual

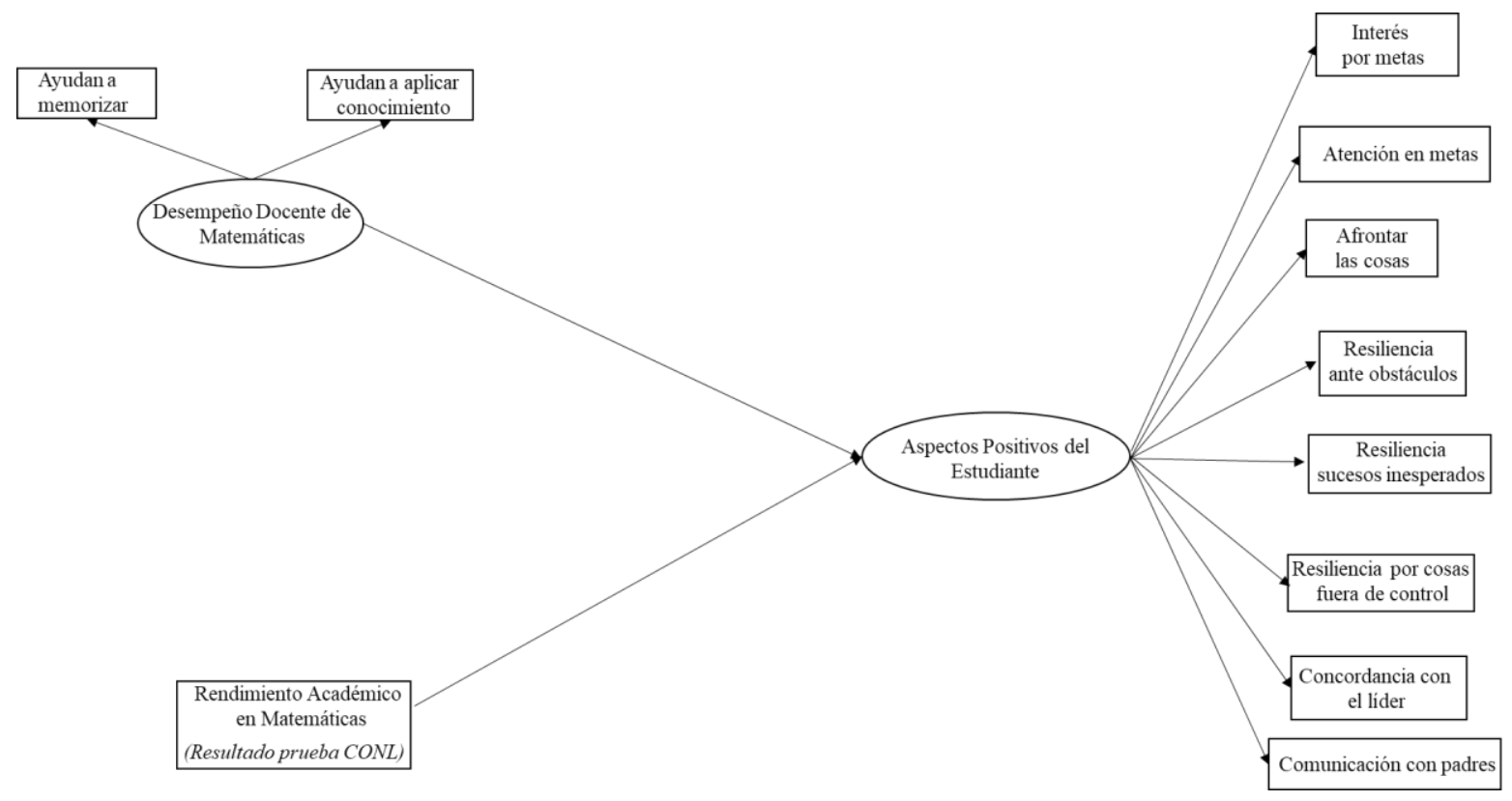

Fuente: Elaboración propia con base en el CONL (2020b)

\section{Resultados}

La aplicación de la evaluación estandarizada se hizo de manera censal a 484 estudiantes del CBMNL, 305 para el plantel San Bernabé, 130 San Nicolás y 49 en Apodaca; $31.81 \%$ para estudiantes de cuarto semestre, $56.20 \%$ en quinto y $11.99 \%$ en sexto semestre (tabla 2).

La tabla 3 muestra el porcentaje de los alumnos por nivel de logro en matemáticas. El $76.3 \%$ se ubicó en el nivel I, es decir, 367 estudiantes; $19.1 \%$ en el nivel II, lo que representa 92 jóvenes; $4.2 \%$ en el nivel III y $0.4 \%$ en el nivel IV. Se observa que 76 de cada 100 alumnos se ubicaron en el nivel de logro "insuficiente", mientras que los alumnos del plantel San Nicolás mostraron mejores resultados.

En la figura 2 se muestra un comparativo de los resultados para matemáticas que se obtuvieron en la prueba Planea aplicada en el 2017 en los subsistemas con sostenimiento estatal y federal en Nuevo León. Se aprecia que en el nivel I se ubicó $76.1 \%$ de los alumnos de los subsistemas federales y $79 \%$ de estudiantes de subsistemas estatales; en el nivel II el porcentaje fue de $16.1 \%$ y $16.7 \%$, respectivamente. Para los niveles III y IV los subsistemas federales registraron $5.8 \%$ y $2 \%$, mientras que los subsistemas estatales apuntaron $3.5 \%$ y $0.9 \%$. Aunque es alta, la proporción de alumnos del CBMNL que se ubica en el nivel de 
logro "insuficiente" en matemáticas, $76.3 \%$, en solo tres años de existencia, es similar a la registrada en Planea 2017 en los planteles federales y estatales.

Tabla 2. Distribución de alumnos del CBMNL por plantel y semestre

\begin{tabular}{|c|c|c|c|c|}
\hline & \multicolumn{4}{|c|}{ Alumnos } \\
\hline Plantel & Total & Cuarto & Quinto & Sexto \\
\hline San Bernabé & 305 & 102 & 145 & 58 \\
\hline San Nicolás & 130 & 33 & 97 & 0 \\
\hline Apodaca & 49 & 19 & 30 & 0 \\
\hline Total & 484 & 154 & 272 & 58 \\
\hline
\end{tabular}

Fuente: Elaboración propia con base en el CONL (2020b)

Tabla 3. Porcentaje de alumnos por nivel de logro en matemáticas

\begin{tabular}{|l|c|c|c|c|}
\hline \multicolumn{1}{|c|}{ Plantel } & I & II & III & IV \\
\hline San Bernabé & $81.50 \%$ & $15.20 \%$ & $3.30 \%$ & $0 \%$ \\
\hline San Nicolás & $64.60 \%$ & $28.50 \%$ & $6.20 \%$ & $0.80 \%$ \\
\hline Apodaca & $75.50 \%$ & $18.40 \%$ & $4.10 \%$ & $2 \%$ \\
\hline \multicolumn{1}{|c|}{ Total } & $76.30 \%$ & $19.10 \%$ & $4.20 \%$ & $0.40 \%$ \\
\hline
\end{tabular}

Fuente: Elaboración propia con base en el CONL (2020b)

Figura 2. Comparativo de resultados

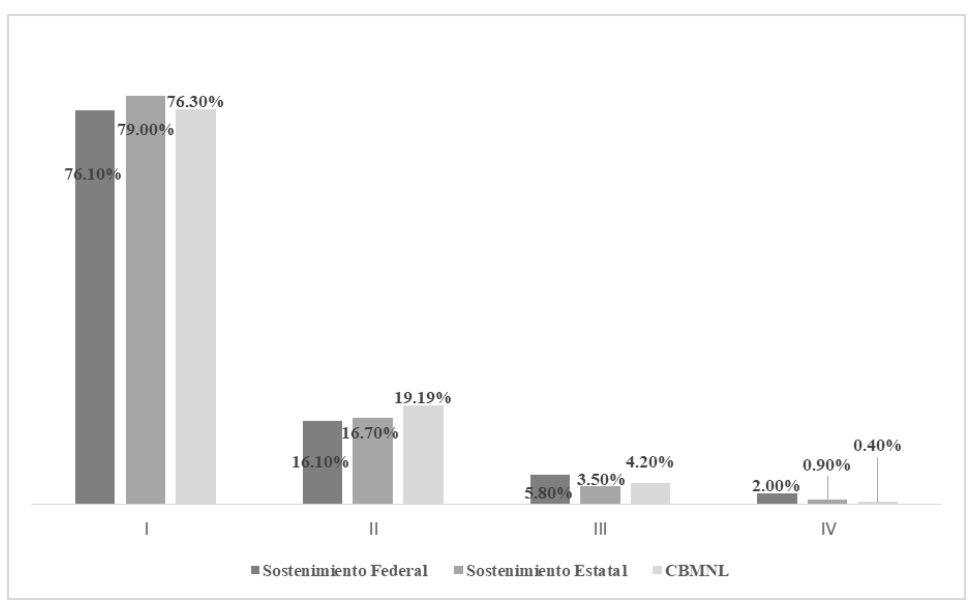

Fuente: Elaboración propia con base en INEE (2017) y CONL (2020b) 
Tabla 4. Porcentaje de alumnos por desempeño docente de matemáticas (ejercicios que ayudan a memorizar) y aspectos positivos del estudiante

\begin{tabular}{|l|c|c|c|c|c|}
\hline \multicolumn{5}{|c|}{ Los maestros de matemáticas dejan ejercicios que ayudan a memorizar conceptos y } \\
procedimientos \\
\hline \multicolumn{5}{|c|}{ Alguna vez me obsesioné con una idea o meta por un tiempo corto, pero más tarde } \\
& $\begin{array}{c}\text { No me } \\
\text { describe }\end{array}$ & $\begin{array}{c}\text { Me } \\
\text { describe } \\
\text { poco }\end{array}$ & describe & $\begin{array}{c}\text { Me } \\
\text { describe } \\
\text { mucho }\end{array}$ & $\begin{array}{c}\text { Me } \\
\text { totalmente }\end{array}$ \\
\hline Nunca & $0.84 \%$ & $0.63 \%$ & $1.47 \%$ & $1.26 \%$ & $0.21 \%$ \\
\hline Algunas veces & $3.79 \%$ & $11.16 \%$ & $8.21 \%$ & $1.68 \%$ & $2.53 \%$ \\
\hline Frecuentemente & $9.68 \%$ & $13.89 \%$ & $11.79 \%$ & $2.95 \%$ & $2.11 \%$ \\
\hline Siempre & $7.37 \%$ & $8.21 \%$ & $5.89 \%$ & $2.95 \%$ & $2.74 \%$ \\
\hline No contestó & $0.21 \%$ & $0.21 \%$ & $0.21 \%$ & $0.00 \%$ & $0.00 \%$ \\
\hline
\end{tabular}

Fuente: Elaboración propia con base en el CONL (2020b)

Tabla 5. Porcentaje de alumnos por desempeño docente de matemáticas (ejercicios que ayudan a memorizar) y aspectos positivos del estudiante

\begin{tabular}{|l|c|c|c|c|c|}
\hline \multicolumn{5}{|c|}{ Tengo dificultad para mantener mi atención en metas que requieren varios meses } \\
& $\begin{array}{c}\text { No me } \\
\text { describe }\end{array}$ & $\begin{array}{c}\text { Me } \\
\text { describe } \\
\text { poco }\end{array}$ & $\begin{array}{c}\text { Me } \\
\text { describe }\end{array}$ & $\begin{array}{c}\text { Me } \\
\text { describe } \\
\text { mucho }\end{array}$ & $\begin{array}{c}\text { Me } \\
\text { describe } \\
\text { totalmente }\end{array}$ \\
\hline Nunca & $1.68 \%$ & $1.26 \%$ & $0.84 \%$ & $0.42 \%$ & $0.00 \%$ \\
\hline Algunas veces & $7.97 \%$ & $10.90 \%$ & $5.03 \%$ & $2.52 \%$ & $0.84 \%$ \\
\hline Frecuentemente & $11.74 \%$ & $15.93 \%$ & $8.60 \%$ & $3.56 \%$ & $0.84 \%$ \\
\hline Siempre & $12.37 \%$ & $8.18 \%$ & $4.40 \%$ & $1.68 \%$ & $0.63 \%$ \\
\hline No contestó & $0.21 \%$ & $0.21 \%$ & $0.21 \%$ & $0.00 \%$ & $0.00 \%$ \\
\hline Soy una persona que se enoja cuando me ponen obstáculos a lo que pretendo hacer \\
\hline \multicolumn{2}{|c|}{$\begin{array}{c}\text { No me } \\
\text { describe }\end{array}$} & $\begin{array}{c}\text { Me } \\
\text { describe }\end{array}$ & $\begin{array}{c}\text { Me } \\
\text { describe }\end{array}$ & $\begin{array}{c}\text { Me } \\
\text { describe } \\
\text { mucho }\end{array}$ & $\begin{array}{c}\text { Me } \\
\text { describe } \\
\text { totalmente }\end{array}$ \\
\hline
\end{tabular}




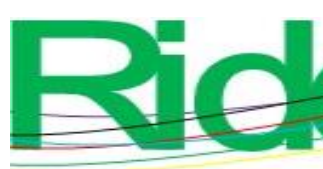

Revista Iberoamericana para la Investigación y el Desarrollo Educativo ISSN 2007 - 7467

\begin{tabular}{|c|c|c|c|c|c|}
\hline Nunca & $0.84 \%$ & $1.68 \%$ & $1.05 \%$ & $0.42 \%$ & $0.21 \%$ \\
\hline Algunas veces & $7.98 \%$ & $9.87 \%$ & $4.62 \%$ & $2.52 \%$ & $2.31 \%$ \\
\hline Frecuentemente & $11.34 \%$ & $17.23 \%$ & $6.51 \%$ & $2.31 \%$ & $3.15 \%$ \\
\hline Siempre & $8.19 \%$ & $10.08 \%$ & $4.41 \%$ & $2.52 \%$ & $2.10 \%$ \\
\hline No contestó & $0.63 \%$ & $0.00 \%$ & $0.00 \%$ & $0.00 \%$ & $0.00 \%$ \\
\hline \multicolumn{6}{|c|}{ Frecuentemente tengo conflictos con el líder de mi grupo de trabajo } \\
\hline & $\begin{array}{l}\text { No me } \\
\text { describe }\end{array}$ & $\begin{array}{c}\mathrm{Me} \\
\text { describe } \\
\text { poco }\end{array}$ & $\begin{array}{c}\text { Me } \\
\text { describe }\end{array}$ & $\begin{array}{c}\mathrm{Me} \\
\text { describe } \\
\text { mucho }\end{array}$ & $\begin{array}{c}\mathrm{Me} \\
\text { describe } \\
\text { totalmente }\end{array}$ \\
\hline Nunca & $3.56 \%$ & $0.00 \%$ & $0.63 \%$ & $0.21 \%$ & $0.00 \%$ \\
\hline Algunas veces & $17.82 \%$ & $6.08 \%$ & $1.68 \%$ & $1.47 \%$ & $0.21 \%$ \\
\hline Frecuentemente & $25.16 \%$ & $9.64 \%$ & $3.35 \%$ & $1.68 \%$ & $0.63 \%$ \\
\hline Siempre & $17.61 \%$ & $5.66 \%$ & $0.84 \%$ & $2.10 \%$ & $1.05 \%$ \\
\hline No contestó & $0.42 \%$ & $0.21 \%$ & $0.00 \%$ & $0.00 \%$ & $0.00 \%$ \\
\hline \multicolumn{6}{|c|}{ Tengo dificultades para comunicarme con mis padres } \\
\hline & $\begin{array}{l}\text { No me } \\
\text { describe }\end{array}$ & $\begin{array}{c}\mathrm{Me} \\
\text { describe } \\
\text { poco }\end{array}$ & $\begin{array}{c}\text { Me } \\
\text { describe }\end{array}$ & $\begin{array}{c}\mathrm{Me} \\
\text { describe } \\
\text { mucho }\end{array}$ & $\begin{array}{c}\mathrm{Me} \\
\text { describe } \\
\text { totalmente }\end{array}$ \\
\hline Nunca & $2.10 \%$ & $1.05 \%$ & $0.63 \%$ & $0.21 \%$ & $0.42 \%$ \\
\hline Algunas veces & $13.21 \%$ & $6.92 \%$ & $3.77 \%$ & $1.68 \%$ & $1.68 \%$ \\
\hline Frecuentemente & $17.82 \%$ & $12.79 \%$ & $7.13 \%$ & $2.52 \%$ & $0.42 \%$ \\
\hline Siempre & $14.68 \%$ & $5.24 \%$ & $3.56 \%$ & $2.31 \%$ & $1.47 \%$ \\
\hline No contestó & $0.21 \%$ & $0.00 \%$ & $0.00 \%$ & $0.21 \%$ & $0.00 \%$ \\
\hline
\end{tabular}

Fuente: Elaboración propia con base en el CONL (2020b) 
Tabla 6. Porcentaje de alumnos por desempeño docente de matemáticas (ejercicios que ayudan a memorizar) y aspectos positivos del estudiante.

\begin{tabular}{|l|c|c|c|c|c|}
\hline \multicolumn{5}{|c|}{ ¿Con qué frecuencia me afectó algo que me ocurrió inesperadamente en el último } \\
& $\begin{array}{c}\text { No me } \\
\text { describe }\end{array}$ & $\begin{array}{c}\text { Me } \\
\text { describe } \\
\text { poco }\end{array}$ & $\begin{array}{c}\text { Me } \\
\text { describe }\end{array}$ & $\begin{array}{c}\text { Me } \\
\text { describe } \\
\text { mucho }\end{array}$ & $\begin{array}{c}\text { Me } \\
\text { describe } \\
\text { totalmente }\end{array}$ \\
\hline Nunca & $0.42 \%$ & $2.51 \%$ & $1.05 \%$ & $0.21 \%$ & $0.21 \%$ \\
\hline Algunas veces & $4.81 \%$ & $12.97 \%$ & $5.86 \%$ & $3.56 \%$ & $0.00 \%$ \\
\hline Frecuentemente & $9.21 \%$ & $21.76 \%$ & $7.11 \%$ & $2.51 \%$ & $0.00 \%$ \\
\hline Siempre & $7.74 \%$ & $13.18 \%$ & $3.97 \%$ & $1.88 \%$ & $0.42 \%$ \\
\hline No contestó & $0.42 \%$ & $0.00 \%$ & $0.21 \%$ & $0.00 \%$ & $0.00 \%$ \\
\hline
\end{tabular}

¿Con qué frecuencia pensé que no podría afrontar todas las cosas que tenía que hacer en el último mes?

\begin{tabular}{|c|c|c|c|c|c|}
\hline & $\begin{array}{l}\text { No me } \\
\text { describe }\end{array}$ & $\begin{array}{c}\mathrm{Me} \\
\text { describe } \\
\text { poco }\end{array}$ & $\begin{array}{c}\mathrm{Me} \\
\text { describe }\end{array}$ & $\begin{array}{c}\text { Me } \\
\text { describe } \\
\text { mucho }\end{array}$ & $\begin{array}{c}\mathrm{Me} \\
\text { describe } \\
\text { totalmente }\end{array}$ \\
\hline Nunca & $1.47 \%$ & $1.26 \%$ & $1.05 \%$ & $0.21 \%$ & $0.21 \%$ \\
\hline Algunas veces & $5.25 \%$ & $12.39 \%$ & $7.98 \%$ & $1.05 \%$ & $0.42 \%$ \\
\hline Frecuentemente & $8.40 \%$ & $18.70 \%$ & $10.29 \%$ & $3.36 \%$ & $0.00 \%$ \\
\hline Siempre & $7.35 \%$ & $12.39 \%$ & $5.46 \%$ & $1.47 \%$ & $0.63 \%$ \\
\hline No contestó & $0.42 \%$ & $0.21 \%$ & $0.00 \%$ & $0.00 \%$ & $0.00 \%$ \\
\hline \multicolumn{6}{|c|}{$\begin{array}{r}\text { ¿Con qué frecuencia me enojé porque las cosas que me c } \\
\text { mi control en el último mes? }\end{array}$} \\
\hline & $\begin{array}{l}\text { No me } \\
\text { describe }\end{array}$ & $\begin{array}{c}\mathrm{Me} \\
\text { describe } \\
\text { poco }\end{array}$ & $\begin{array}{c}\mathrm{Me} \\
\text { describe }\end{array}$ & $\begin{array}{c}\text { Me } \\
\text { describe } \\
\text { mucho }\end{array}$ & $\begin{array}{c}\mathrm{Me} \\
\text { describe } \\
\text { totalmente }\end{array}$ \\
\hline Nunca & $1.05 \%$ & $2.09 \%$ & $0.63 \%$ & $0.42 \%$ & $0.21 \%$ \\
\hline Algunas veces & $6.90 \%$ & $9.21 \%$ & $7.11 \%$ & $3.97 \%$ & $0.00 \%$ \\
\hline Frecuentemente & $11.92 \%$ & $14.85 \%$ & $9.21 \%$ & $4.60 \%$ & $0.00 \%$ \\
\hline Siempre & $8.37 \%$ & $10.25 \%$ & $4.60 \%$ & $3.35 \%$ & $0.63 \%$ \\
\hline No contestó & $0.42 \%$ & $0.21 \%$ & $0.00 \%$ & $0.00 \%$ & $0.00 \%$ \\
\hline
\end{tabular}


Fuente: Elaboración propia con base en el CONL (2020b)

Tabla 7. Porcentaje de alumnos por desempeño docente de matemáticas (ejercicios que ayudan a aplicar conocimientos) y aspectos positivos del estudiante

Los maestros de matemáticas dejan ejercicios y tareas que ayudan a aplicar conocimientos adquiridos en clase a problemas o situaciones

Alguna vez me obsesioné con una idea o meta por un tiempo corto, pero más tarde perdí el interés

\begin{tabular}{|l|c|c|c|c|c|}
\hline & $\begin{array}{c}\text { No me } \\
\text { describe }\end{array}$ & $\begin{array}{c}\text { Me describe } \\
\text { poco }\end{array}$ & Me describe & $\begin{array}{c}\text { Me describe } \\
\text { mucho }\end{array}$ & $\begin{array}{c}\text { Me describe } \\
\text { totalmente }\end{array}$ \\
\hline Nunca & $1.05 \%$ & $0.84 \%$ & $1.05 \%$ & $0.63 \%$ & $0.21 \%$ \\
\hline Algunas veces & $3.37 \%$ & $8.84 \%$ & $7.58 \%$ & $1.89 \%$ & $1.26 \%$ \\
\hline Frecuentemente & $8.42 \%$ & $16.42 \%$ & $12.21 \%$ & $4.21 \%$ & $3.37 \%$ \\
\hline Siempre & $9.05 \%$ & $8.00 \%$ & $6.11 \%$ & $2.11 \%$ & $2.74 \%$ \\
\hline No contestó & $0.00 \%$ & $0.21 \%$ & $0.42 \%$ & $0.00 \%$ & $0.00 \%$ \\
\hline
\end{tabular}

Tengo dificultad para mantener mi atención en metas que requieren varios meses para ser terminadas

\begin{tabular}{|l|c|c|c|c|c|}
\hline & $\begin{array}{c}\text { No me } \\
\text { describe }\end{array}$ & $\begin{array}{c}\text { Me describe } \\
\text { poco }\end{array}$ & Me describe & $\begin{array}{c}\text { Me describe } \\
\text { mucho }\end{array}$ & $\begin{array}{c}\text { Me describe } \\
\text { totalmente }\end{array}$ \\
\hline Nunca & $1.68 \%$ & $1.26 \%$ & $0.63 \%$ & $0.21 \%$ & $0.00 \%$ \\
\hline Algunas veces & $5.67 \%$ & $9.45 \%$ & $4.41 \%$ & $2.94 \%$ & $0.63 \%$ \\
\hline Frecuentemente & $14.29 \%$ & $16.39 \%$ & $8.61 \%$ & $4.41 \%$ & $0.84 \%$ \\
\hline Siempre & $12.39 \%$ & $8.82 \%$ & $5.25 \%$ & $0.63 \%$ & $0.84 \%$ \\
\hline No contestó & $0.00 \%$ & $0.42 \%$ & $0.21 \%$ & $0.00 \%$ & $0.00 \%$ \\
\hline
\end{tabular}

Soy una persona que se enoja cuando me ponen obstáculos a lo que pretendo hacer

\begin{tabular}{|l|c|c|c|c|c|}
\hline & $\begin{array}{c}\text { No me } \\
\text { describe }\end{array}$ & $\begin{array}{c}\text { Me describe } \\
\text { poco }\end{array}$ & Me describe & $\begin{array}{c}\text { Me describe } \\
\text { mucho }\end{array}$ & $\begin{array}{c}\text { Me describe } \\
\text { totalmente }\end{array}$ \\
\hline Nunca & $1.27 \%$ & $0.84 \%$ & $1.05 \%$ & $0.21 \%$ & $0.21 \%$ \\
\hline Algunas veces & $5.27 \%$ & $10.13 \%$ & $2.53 \%$ & $3.38 \%$ & $1.90 \%$ \\
\hline Frecuentemente & $13.08 \%$ & $16.24 \%$ & $9.28 \%$ & $2.53 \%$ & $3.59 \%$ \\
\hline Siempre & $9.07 \%$ & $11.39 \%$ & $3.59 \%$ & $1.69 \%$ & $2.11 \%$ \\
\hline No contestó & $0.42 \%$ & $0.21 \%$ & $0.00 \%$ & $0.00 \%$ & $0.00 \%$ \\
\hline
\end{tabular}


Fuente: Elaboración propia con base en el CONL (2020b)

Tabla 8. Porcentaje de alumnos por desempeño docente de matemáticas (ejercicios que ayudan a aplicar conocimientos) y aspectos positivos del estudiante

\begin{tabular}{|c|c|c|c|c|c|}
\hline \multicolumn{6}{|c|}{ Frecuentemente tengo conflictos con el líder de mi grupo de trabajo } \\
\hline & $\begin{array}{c}\text { No me } \\
\text { describe }\end{array}$ & $\begin{array}{c}\text { Me describe } \\
\text { poco }\end{array}$ & Me describe & $\begin{array}{c}\text { Me describe } \\
\text { mucho }\end{array}$ & $\begin{array}{l}\text { Me describe } \\
\text { totalmente }\end{array}$ \\
\hline Nunca & $2.74 \%$ & $0.42 \%$ & $0.21 \%$ & $0.21 \%$ & $0.21 \%$ \\
\hline Algunas veces & $13.68 \%$ & $5.05 \%$ & $2.53 \%$ & $1.47 \%$ & $0.21 \%$ \\
\hline Frecuentemente & $30.32 \%$ & $9.47 \%$ & $2.53 \%$ & $1.68 \%$ & $0.63 \%$ \\
\hline Siempre & $17.47 \%$ & $6.32 \%$ & $1.26 \%$ & $2.11 \%$ & $0.84 \%$ \\
\hline No contestó & $0.42 \%$ & $0.21 \%$ & $0.00 \%$ & $0.00 \%$ & $0.00 \%$ \\
\hline \multicolumn{6}{|c|}{ Tengo dificultades para comunicarme con mis padres } \\
\hline & $\begin{array}{l}\text { No me } \\
\text { describe }\end{array}$ & $\begin{array}{c}\text { Me describe } \\
\text { poco }\end{array}$ & Me describe & $\begin{array}{c}\text { Me describe } \\
\text { mucho }\end{array}$ & $\begin{array}{l}\text { Me describe } \\
\text { totalmente }\end{array}$ \\
\hline Nunca & $1.47 \%$ & $1.05 \%$ & $0.84 \%$ & $0.21 \%$ & $0.21 \%$ \\
\hline Algunas veces & $10.50 \%$ & $6.09 \%$ & $3.15 \%$ & $2.10 \%$ & $1.26 \%$ \\
\hline Frecuentemente & $21.85 \%$ & $11.34 \%$ & $7.56 \%$ & $2.31 \%$ & $1.47 \%$ \\
\hline Siempre & $13.87 \%$ & $7.14 \%$ & $3.57 \%$ & $2.31 \%$ & $1.05 \%$ \\
\hline No contestó & $0.42 \%$ & $0.21 \%$ & $0.00 \%$ & $0.00 \%$ & $0.00 \%$ \\
\hline \multicolumn{6}{|c|}{ ¿Con qué frecuencia me afectó algo que me ocurrió inesperadamente en el último mes? } \\
\hline & $\begin{array}{l}\text { No me } \\
\text { describe }\end{array}$ & $\begin{array}{c}\text { Me describe } \\
\text { poco }\end{array}$ & Me describe & $\begin{array}{c}\text { Me describe } \\
\text { mucho }\end{array}$ & $\begin{array}{l}\text { Me describe } \\
\text { totalmente }\end{array}$ \\
\hline Nunca & $0.63 \%$ & $1.89 \%$ & $0.84 \%$ & $0.21 \%$ & $0.21 \%$ \\
\hline Algunas veces & $4.41 \%$ & $10.92 \%$ & $5.04 \%$ & $2.73 \%$ & $0.00 \%$ \\
\hline Frecuentemente & $9.66 \%$ & $24.58 \%$ & $7.77 \%$ & $2.52 \%$ & $0.00 \%$ \\
\hline Siempre & $7.35 \%$ & $12.82 \%$ & $4.62 \%$ & $2.73 \%$ & $0.42 \%$ \\
\hline No contestó & $0.42 \%$ & $0.21 \%$ & $0.00 \%$ & $0.00 \%$ & $0.00 \%$ \\
\hline \multicolumn{6}{|c|}{$\begin{array}{c}\text { ¿Con qué frecuencia pensé que no podría afrontar todas las cosas que tenía que hacer en el } \\
\text { último mes? }\end{array}$} \\
\hline & $\begin{array}{l}\text { No me } \\
\text { describe }\end{array}$ & $\begin{array}{c}\text { Me describe } \\
\text { poco }\end{array}$ & Me describe & $\begin{array}{c}\text { Me describe } \\
\text { mucho }\end{array}$ & $\begin{array}{l}\text { Me describe } \\
\text { totalmente }\end{array}$ \\
\hline
\end{tabular}




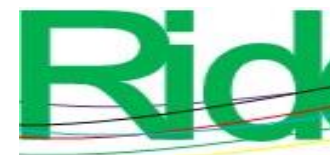

Revista Iberoamericana para la Investigación y el Desarrollo Educativo ISSN 2007 - 7467

\begin{tabular}{|l|c|c|c|c|c|}
\hline Nunca & $1.27 \%$ & $1.69 \%$ & $0.42 \%$ & $0.21 \%$ & $0.21 \%$ \\
\hline Algunas veces & $4.43 \%$ & $10.13 \%$ & $7.17 \%$ & $1.48 \%$ & $0.00 \%$ \\
\hline Frecuentemente & $9.07 \%$ & $21.10 \%$ & $11.81 \%$ & $2.11 \%$ & $0.42 \%$ \\
\hline Siempre & $7.81 \%$ & $11.60 \%$ & $5.49 \%$ & $2.32 \%$ & $0.63 \%$ \\
\hline No contestó & $0.42 \%$ & $0.21 \%$ & $0.00 \%$ & $0.00 \%$ & $0.00 \%$ \\
\hline
\end{tabular}

Fuente: Elaboración propia con base en el CONL (2020b)

Tabla 9. Porcentaje de alumnos por desempeño docente de matemáticas (ejercicios que ayudan a aplicar conocimientos) y aspectos positivos del estudiante

\begin{tabular}{|l|c|c|c|c|c|}
\hline \multicolumn{5}{|c|}{ ¿Con qué frecuencia me enojé porque las cosas que me ocurrieron estaban fuera de mi } \\
control en el último mes? \\
\hline & $\begin{array}{c}\text { No me } \\
\text { describe }\end{array}$ & $\begin{array}{c}\text { Me describe } \\
\text { poco }\end{array}$ & Me describe & $\begin{array}{c}\text { Me describe } \\
\text { mucho }\end{array}$ & $\begin{array}{c}\text { Me describe } \\
\text { totalmente }\end{array}$ \\
\hline Nunca & $0.84 \%$ & $1.26 \%$ & $0.84 \%$ & $0.84 \%$ & $0.00 \%$ \\
\hline Algunas veces & $5.46 \%$ & $8.19 \%$ & $6.30 \%$ & $3.15 \%$ & $0.00 \%$ \\
\hline Frecuentemente & $12.61 \%$ & $17.02 \%$ & $10.29 \%$ & $4.41 \%$ & $0.21 \%$ \\
\hline Siempre & $9.45 \%$ & $9.87 \%$ & $4.20 \%$ & $3.78 \%$ & $0.63 \%$ \\
\hline No contestó & $0.42 \%$ & $0.21 \%$ & $0.00 \%$ & $0.00 \%$ & $0.00 \%$ \\
\hline
\end{tabular}

Fuente: Elaboración propia con base en el CONL (2020b) 
Tabla 10. Porcentaje de alumnos por rendimiento académico en matemáticas y aspectos positivos del estudiante

\begin{tabular}{|l|c|c|c|c|c|}
\hline \multirow{2}{*}{} & \multicolumn{5}{|c|}{ Alguna vez me obsesioné con una idea o meta por un tiempo corto, pero más tarde } \\
& $\begin{array}{l}\text { No me } \\
\text { describe }\end{array}$ & $\begin{array}{c}\text { Me describe } \\
\text { poco }\end{array}$ & Me describe & $\begin{array}{c}\text { Me describe } \\
\text { mucho }\end{array}$ & $\begin{array}{c}\text { Me describe } \\
\text { totalmente }\end{array}$ \\
\hline Nivel I & $18.26 \%$ & $23.57 \%$ & $21.02 \%$ & $6.58 \%$ & $6.37 \%$ \\
\hline Nivel II & $3.18 \%$ & $8.49 \%$ & $4.88 \%$ & $1.91 \%$ & $1.06 \%$ \\
\hline Nivel III & $0.64 \%$ & $1.91 \%$ & $1.27 \%$ & $0.21 \%$ & $0.21 \%$ \\
\hline Nivel IV & $0.00 \%$ & $0.42 \%$ & $0.00 \%$ & $0.00 \%$ & $0.00 \%$ \\
\hline \multirow{2}{*}{ Tengo dificultad para mantener mi atención en metas que requieren varios meses } \\
\hline
\end{tabular}

Fuente: Elaboración propia con base en el CONL (2020b) 


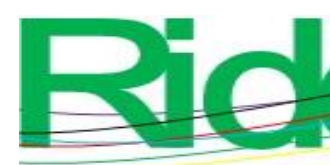

\section{Revista Iberoamericana para la Investigación y el Desarrollo Educativo ISSN 2007 - 7467}

Tabla 11. Porcentaje de alumnos por rendimiento académico en matemáticas $\mathrm{y}$ aspectos positivos del estudiante

\begin{tabular}{|c|c|c|c|c|c|}
\hline & \multicolumn{5}{|c|}{$\begin{array}{l}\text { Soy una persona que se enoja cuando me ponen obstáculos a lo que pretendo } \\
\text { hacer }\end{array}$} \\
\hline & $\begin{array}{l}\text { No me } \\
\text { describe }\end{array}$ & $\begin{array}{l}\text { Me describe } \\
\text { poco }\end{array}$ & Me describe & $\begin{array}{l}\text { Me describe } \\
\text { mucho }\end{array}$ & $\begin{array}{l}\text { Me describe } \\
\text { totalmente }\end{array}$ \\
\hline Nivel I & $23.11 \%$ & $29.37 \%$ & $13.39 \%$ & $7.34 \%$ & $5.40 \%$ \\
\hline Nivel II & $4.54 \%$ & $7.99 \%$ & $2.38 \%$ & $0.43 \%$ & $1.30 \%$ \\
\hline Nivel III & $1.08 \%$ & $1.30 \%$ & $1.08 \%$ & $0.00 \%$ & $0.86 \%$ \\
\hline \multirow[t]{3}{*}{ Nivel IV } & $0.22 \%$ & $0.22 \%$ & $0.00 \%$ & $0.00 \%$ & $0.00 \%$ \\
\hline & \multicolumn{5}{|c|}{ Frecuentemente tengo conflictos con el líder de mi grupo de trabajo } \\
\hline & $\begin{array}{l}\text { No me } \\
\text { describe }\end{array}$ & $\begin{array}{l}\text { Me describe } \\
\text { poco }\end{array}$ & Me describe & $\begin{array}{l}\text { Me describe } \\
\text { mucho }\end{array}$ & $\begin{array}{l}\text { Me describe } \\
\text { totalmente }\end{array}$ \\
\hline Nivel I & $50.83 \%$ & $14.38 \%$ & $5.00 \%$ & $4.17 \%$ & $1.46 \%$ \\
\hline Nivel II & $10.83 \%$ & $6.25 \%$ & $1.04 \%$ & $1.04 \%$ & $0.42 \%$ \\
\hline Nivel III & $2.08 \%$ & $0.83 \%$ & $0.42 \%$ & $0.63 \%$ & $0.21 \%$ \\
\hline \multirow[t]{3}{*}{ Nivel IV } & $0.00 \%$ & $0.42 \%$ & $0.00 \%$ & $0.00 \%$ & $0.00 \%$ \\
\hline & \multicolumn{5}{|c|}{ Tengo dificultades para comunicarme con mis padres } \\
\hline & $\begin{array}{l}\text { No me } \\
\text { describe }\end{array}$ & $\begin{array}{l}\text { Me describe } \\
\text { poco }\end{array}$ & Me describe & $\begin{array}{l}\text { Me describe } \\
\text { mucho }\end{array}$ & $\begin{array}{l}\text { Me describe } \\
\text { totalmente }\end{array}$ \\
\hline Nivel I & $37.29 \%$ & $18.54 \%$ & $11.46 \%$ & $6.04 \%$ & $2.92 \%$ \\
\hline Nivel II & $9.17 \%$ & $5.83 \%$ & $2.50 \%$ & $0.83 \%$ & $0.83 \%$ \\
\hline Nivel III & $1.67 \%$ & $1.04 \%$ & $1.04 \%$ & $0.21 \%$ & $0.21 \%$ \\
\hline \multirow[t]{3}{*}{ Nivel IV } & $0.00 \%$ & $0.21 \%$ & $0.21 \%$ & $0.00 \%$ & $0.00 \%$ \\
\hline & \multicolumn{5}{|c|}{$\begin{array}{c}\text { ¿Con qué frecuencia me afectó algo que me ocurrió inesperadamente en el } \\
\text { último mes? }\end{array}$} \\
\hline & $\begin{array}{l}\text { No me } \\
\text { describe }\end{array}$ & $\begin{array}{l}\text { Me describe } \\
\text { poco }\end{array}$ & Me describe & $\begin{array}{c}\text { Me describe } \\
\text { mucho }\end{array}$ & $\begin{array}{c}\text { Me describe } \\
\text { totalmente }\end{array}$ \\
\hline Nivel I & $17.08 \%$ & $38.13 \%$ & $13.75 \%$ & $7.08 \%$ & $0.21 \%$ \\
\hline Nivel II & $4.79 \%$ & $10.00 \%$ & $3.13 \%$ & $1.04 \%$ & $0.21 \%$ \\
\hline Nivel III & $0.42 \%$ & $2.08 \%$ & $1.46 \%$ & $0.00 \%$ & $0.21 \%$ \\
\hline Nivel IV & $0.21 \%$ & $0.21 \%$ & $0.00 \%$ & $0.00 \%$ & $0.00 \%$ \\
\hline
\end{tabular}




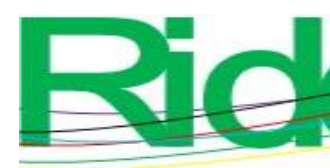

Revista Iberoamericana para la Investigación y el Desarrollo Educativo ISSN 2007 - 7467

\begin{tabular}{|l|c|c|c|c|c|}
\hline \multirow{2}{*}{} & \multicolumn{5}{|c|}{$¿$ Con qué frecuencia pensé que no podría afrontar todas las cosas que tenía } \\
& $\begin{array}{c}\text { No me } \\
\text { que hacer en el último mes? }\end{array}$ & $\begin{array}{c}\text { Me describe } \\
\text { poco }\end{array}$ & Me describe & $\begin{array}{c}\text { Me describe } \\
\text { mucho }\end{array}$ & $\begin{array}{c}\text { Me describe } \\
\text { totalmente }\end{array}$ \\
\hline Nivel I & $17.57 \%$ & $33.68 \%$ & $19.25 \%$ & $5.02 \%$ & $0.63 \%$ \\
\hline Nivel II & $4.60 \%$ & $8.79 \%$ & $4.81 \%$ & $0.84 \%$ & $0.21 \%$ \\
\hline Nivel III & $0.42 \%$ & $2.09 \%$ & $0.84 \%$ & $0.42 \%$ & $0.42 \%$ \\
\hline Nivel IV & $0.00 \%$ & $0.42 \%$ & $0.00 \%$ & $0.00 \%$ & $0.00 \%$ \\
\hline
\end{tabular}

Fuente: Elaboración propia con base en el CONL (2020b)

Tabla 12. Porcentaje de alumnos por rendimiento académico en matemáticas y aspectos positivos del estudiante

\begin{tabular}{|l|c|c|c|c|c|}
\hline \multirow{2}{*}{} & \multicolumn{5}{|c|}{ ¿Con qué frecuencia me enojé porque las cosas que me ocurrieron estaban } \\
& $\begin{array}{l}\text { No me } \\
\text { fescribe }\end{array}$ & $\begin{array}{c}\text { Me describe } \\
\text { poco }\end{array}$ & Me describe & $\begin{array}{c}\text { Me describe } \\
\text { mucho }\end{array}$ & $\begin{array}{c}\text { Me describe } \\
\text { totalmente }\end{array}$ \\
\hline Nivel I & $22.71 \%$ & $26.46 \%$ & $16.67 \%$ & $9.79 \%$ & $0.63 \%$ \\
\hline Nivel II & $4.58 \%$ & $8.33 \%$ & $4.38 \%$ & $1.67 \%$ & $0.21 \%$ \\
\hline Nivel III & $0.83 \%$ & $1.88 \%$ & $0.42 \%$ & $1.04 \%$ & $0.00 \%$ \\
\hline Nivel IV & $0.21 \%$ & $0.00 \%$ & $0.21 \%$ & $0.00 \%$ & $0.00 \%$ \\
\hline
\end{tabular}

Fuente: Elaboración propia con base en el CONL (2020b)

De las tablas 4 a la 9 se muestran las distribuciones sobre lo que piensan los alumnos del desempeño docente de matemáticas, particularmente lo relacionado con los ejercicios que ayudan a memorizar conceptos y procedimientos y aquellos que ayudan a aplicar conocimientos adquiridos en problemas o situaciones y los diversos aspectos positivos del estudiante. De las tablas 10 a la 12 se plasma la distribución de alumnos por rendimiento académico en matemáticas y los aspectos positivos.

En seguida, se procedió a obtener los estadísticos descriptivos. Para el presente estudio y con la finalidad de hacer comparaciones con otras variables que miden en escala de cuatro, se adecuó la escala empleada, multiplicándola por cuatro y restándole dos (Muñiz et al., 2011, p. 47). Igualmente, la escala aplicada en las variables que comprenden el factor de aspectos positivos del estudiante fue invertida para hacer asociaciones con el factor y la 

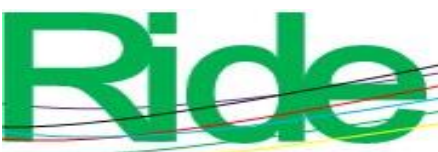

Revista Iberoamericana para la Investigación y el Desarrollo Educativo

ISSN $2007-7467$

variable independientes. Como se aprecia en la tabla 13, la media del constructo dependiente es de 3.63, es decir, los alumnos consideran que sus características personales, referentes todas ellas a los niveles de resiliencia, perseverancia y reconocimiento de la disciplina, se encuentran entre "me describe" y "me describe mucho". El rendimiento académico en matemáticas se ubicó en "básico", aunque la moda fue "insuficiente". El desempeño docente de matemáticas registró una media de 2.74, equivalente a entre "algunas veces" y "frecuentemente".

En la tabla 14 se aprecian las correlaciones entre variables. Resalta la correlación significativa en el nivel 0.01 que hay entre los aspectos positivos del estudiante y el desempeño docente de matemáticas con 0.636 .

Tabla 13. Estadísticos descriptivos.

\begin{tabular}{|c|c|c|c|}
\hline $\begin{array}{c}\text { Constructo / } \\
\text { Variable }\end{array}$ & Media & $\begin{array}{c}\text { Desviación } \\
\text { Estándar }\end{array}$ & $\mathrm{N}$ \\
\hline $\begin{array}{c}\text { Aspectos } \\
\text { positivos del } \\
\text { estudiante }\end{array}$ & 3.6397 & 1.1057 & 484 \\
\hline $\begin{array}{c}\text { Rendimiento } \\
\text { académico en } \\
\text { matemáticas }\end{array}$ & 2.1389 & 0.69612 & 484 \\
\hline $\begin{array}{c}\text { Desempeño } \\
\text { docente de } \\
\text { matemáticas }\end{array}$ & 2.7466 & 1.03841 & 484 \\
\hline
\end{tabular}

Fuente: Elaboración propia con base en el CONL (2020b) 
Tabla 14. Correlaciones

\begin{tabular}{|c|c|c|c|}
\hline Constructo & $\begin{array}{c}\text { Características } \\
\text { personales del } \\
\text { estudiante }\end{array}$ & $\begin{array}{c}\text { Rendimiento } \\
\text { académico } \\
\text { en } \\
\text { matemáticas }\end{array}$ & $\begin{array}{c}\text { Desempeño } \\
\text { docente de } \\
\text { matemáticas }\end{array}$ \\
\hline $\begin{array}{c}\text { Aspectos } \\
\text { positivos del } \\
\text { estudiante }\end{array}$ & 1 & -0.014 & 0.636 \\
\hline $\begin{array}{c}\text { Rendimiento } \\
\text { académico en } \\
\text { matemáticas }\end{array}$ & -0.014 & 1 & 0.008 \\
\hline $\begin{array}{c}\text { Desempeño } \\
\text { docente de } \\
\text { matemáticas }\end{array}$ & 0.636 & 0.008 & 1 \\
\hline
\end{tabular}

Los resultados fueron estadísticamente significativos a un nivel de confianza de $p<0.05$

Fuente: Elaboración propia con base en el CONL (2020b)

En consecuencia, para comprobar las asociaciones entre las variables expuestas en el modelo teórico, se aplicó una técnica estadística de regresión lineal múltiple representada con la ecuación 1.

$$
y=\beta_{0}+\beta_{1} x_{1}+\beta_{2} x_{2}+e
$$

Ecuación 1

Donde $x_{1}=$ Rendimiento académico; $x_{2}=$ Desempeño docente de matemáticas; $y=$ Aspectos positivos del estudiante.

Por consiguiente, en la tabla 15 se aprecia que el modelo tiene un nivel explicativo significativo de $40.3 \%$ de la varianza $\left(\mathrm{R}^{2}\right.$ de 0.403$)$, que, con un valor de $\beta=0.000 ; p=$ 0.001, representa el grado en el que el modelo explica el comportamiento de la variable dependiente con respecto a las independientes, o bien la relación que hay de las $x$ con la $y$, la cual es de $40.3 \%$. 
Tabla 15. Estadísticas de regresión para la ecuación 1

\begin{tabular}{|l|r|}
\hline \multicolumn{2}{|c|}{ Estadísticas de la regresión } \\
\hline $\begin{array}{l}\text { Coeficiente de } \\
\text { correlación múltiple }\end{array}$ & 0.405 \\
\hline $\begin{array}{l}\text { Coeficiente de } \\
\text { determinación } \mathrm{R}^{\wedge} 2\end{array}$ & 0.403 \\
\hline Error típico & 0.85461 \\
\hline Durbin-Watson & 2.078 \\
\hline
\end{tabular}

Fuente: Elaboración propia con base en el CONL (2020b)

Con el valor arrojado, se determina que el modelo que refleja la relación entre "Desempeño docente de matemáticas" y "Rendimiento académico en matemáticas" con "Aspectos positivos del estudiante" es confiable. Por lo tanto, se entiende que los maestros de matemáticas que dejan ejercicios y tareas para memorizar conceptos y procedimientos, así como para aplicar conocimientos adquiridos a problemas o situaciones, y los resultados que los jóvenes obtienen en matemáticas influirán en el interés por las metas trazadas, la atención a estas, afrontar las cosas, la frustración frente a los obstáculos, la resiliencia, el enojo por las cosas fuera del control, los conflictos con el líder y las dificultades de comunicación con los padres de los estudiantes del CBMNL.

La figura 2 refleja las asociaciones que hay de manera directa entre factor y variable independientes con el constructo dependiente. De forma negativa, "Rendimiento académico en matemáticas" tiene un peso de -0.030 , lo que, de manera práctica, no influye, mas hay una tendencia a que resultados positivos afecten los aspectos positivos de los estudiantes del CBMNL. Por el contrario, a mayor desempeño docente de matemáticas mayores aspectos positivos del estudiante del CBMNL. Por lo tanto, se establece la ecuación 2. 
Figura 2. Modelo empírico conceptual

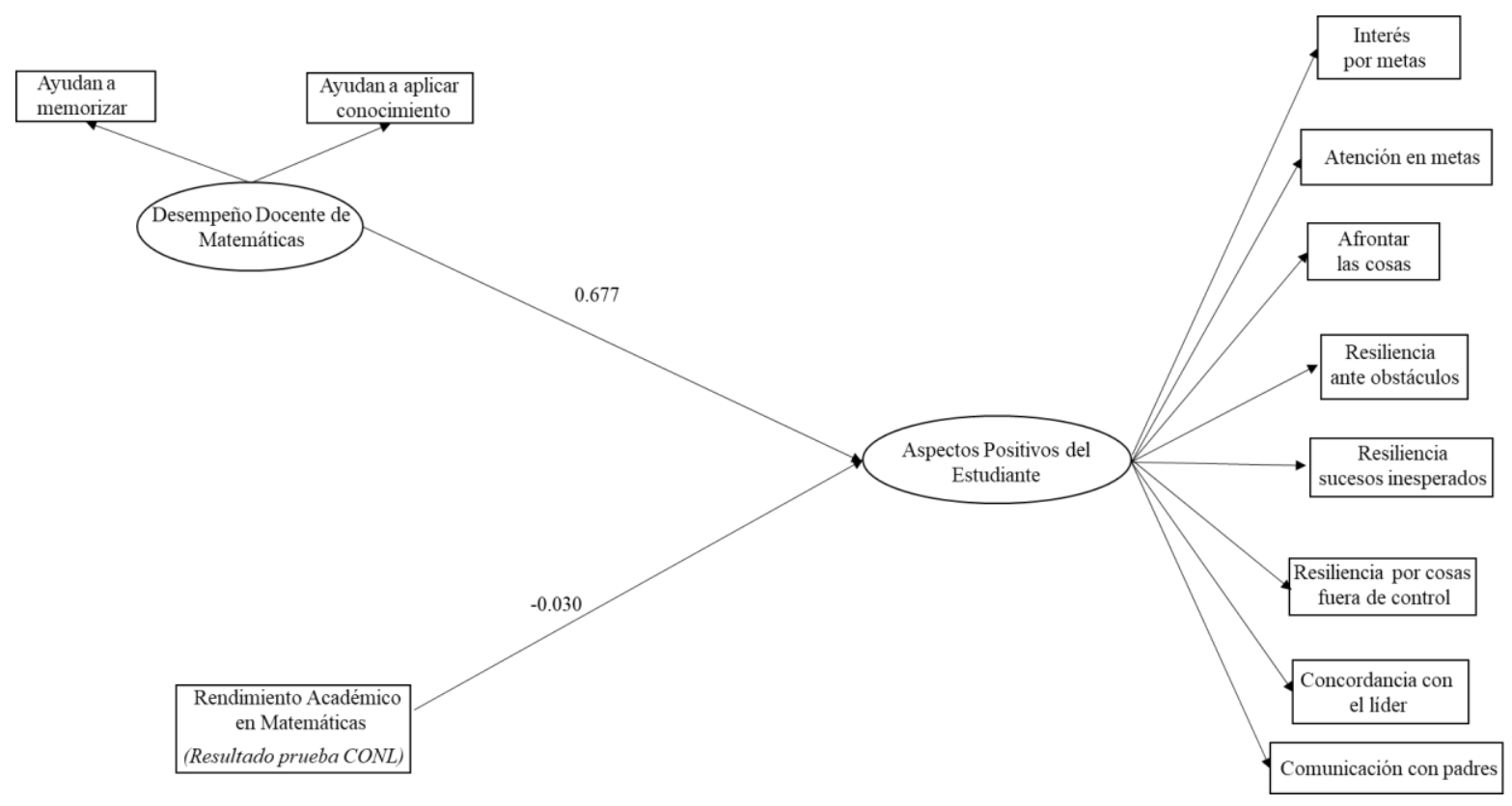

Fuente: Elaboración propia con base en el CONL (2020b)

$$
y=1.843-0.030 x_{1}+0.677 x_{2}
$$

Ecuación 2

\section{Discusión}

Sensato y Lucio (2017) afirman que la EMS desarrolla competencias que incluyen aspectos tanto de conocimientos como de personalidad que lleven a la perfección del alumnado; Tuirán (2017) establece que el bachillerato es responsable de forjar muchos elementos que componen las habilidades socioemocionales.

Así, con base en la información contenida en la figura 2, se aprecia que el desempeño docente de matemáticas compuesto por la aplicación de ejercicios y tareas que ayudan tanto a memorizar conceptos y procedimientos como a aplicar los conocimientos adquiridos a problemas o situaciones influye de manera positiva en los aspectos positivos del estudiante: el interés por las metas, la atención en las metas, afrontar las cosas, resiliencia ante obstáculos, resiliencia por sucesos inesperados, resiliencia por las cosas fuera de control, concordancia con el líder y la comunicación con los padres. Lo anterior ha sido descrito por Gómez (2010), quien afirmó que cuando los docentes aplican ejercicios para que haya mayor comprensión de las matemáticas los alumnos desarrollan ciertos componentes de su personalidad como la perseverancia y el manejo de frustraciones, temores y enojos. De 


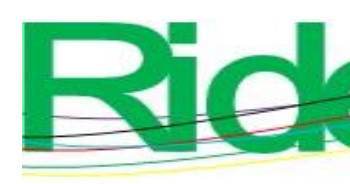

Revista Iberoamericana para la Investigación y el Desarrollo Educativo ISSN 2007 - 7467

manera similar, Tuirán y Hernández (1 de noviembre de 2015) concluyeron que los profesores que utilizan herramientas didácticas efectivas favorecen habilidades socioemocionales como la constancia y la resiliencia en los estudiantes. Silas (2008) agrega que la calidad en la enseñanza de las matemáticas, además de motivar la tenacidad y promover la resiliencia, beneficia la relación entre líder y discípulo pues despierta la admiración hacia los docentes. Por su parte, Campuzano y Libien (2019) consideraron que los instructores de matemáticas son clave para inyectar entusiasmo entre los alumnos y así enfrentar y superar problemas. Y Fernández (2014) suma que el desempeño del profesor incide en la aceptación de reglas y normas por parte del grupo.

Por otra parte, Cerda et al., (2018) publicaron que el trabajo de los docentes de matemáticas en el aula puede estimular la participación, dedicación, asimilación de errores y el nuevo intento por resolver los problemas en los que se haya equivocado el estudiante. Islas y Carranza (2011) y Jaik y Barraza (2011) afirmaron que los trabajos y ejercicios de matemáticas inciden en el interés por esta ciencia. Montes y Machado (2011) y Hernández et al. (2017) aseguran que las estrategias didácticas y los recursos empleados benefician, además de los aspectos cognitivos, los vínculos afectivos, las relaciones sociales y la comunicación; mientras que los docentes de matemáticas que aplican actividades para el manejo de conocimientos y habilidades favorecen aspectos como el autocontrol, la superación de expectativas y la integración armónica entre docentes y alumnos (SEP, 29 de octubre de 2018, p. 4). Rivera et al. (2014) afirmaron que mediante el desempeño y ejemplo los docentes de EMS modelan aspectos personales de los alumnos como resiliencia, perseverancia, dominio de emociones y el entendimiento de la función de sus tutores. Beresaluce, Peiró y Ramos (2014) consideraron que los docentes enseñan a los jóvenes a trazar metas, trabajar para lograrlas y dejarse guiar por sus docentes o padres. Covarrubias y Piña (2004) identificaron que los profesores despiertan en sus alumnos el interés por lograr los objetivos académicos y estar de acuerdo con la disciplina de sus superiores. Zapata (2017) aportó que al momento en que el maestro de matemáticas da retroalimentación envía una señal a los alumnos de liderazgo referencial, que hace que se gane el respeto más fácilmente. A su vez, Venet y Díaz (2018) escribieron que los docentes de matemáticas se vuelven líderes cuando emplean herramientas adecuadas para la enseñanza y mantienen relaciones afectivas con sus alumnos. Dizay y Narváez (2012) publicaron que la orientación académica del docente promueve ciertos aspectos socioemocionales de los alumnos como esforzarse por cumplir las metas fijadas y la resiliencia. Ricoy y Couto (2018) subrayan que mediante el 


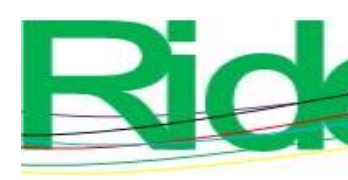

Revista Iberoamericana para la Investigación y el Desarrollo Educativo ISSN 2007 - 7467

trabajo estimulante de los profesores de matemáticas se motiva a los alumnos para que se muestren más interesados en cumplir las metas, fijen la atención en estas y manejen sus emociones frente a obstáculos y sucesos inesperados que acontecen dentro del aula y, probablemente, fuera de ella. Por último, Becerra y Reidl (2015) añaden una mejor interacción con su ambiente familiar, incluida la comunicación entre ellos.

Ahora bien, el rendimiento académico en matemáticas prácticamente no influye con los aspectos positivos del estudiante, lo cual coincide con Gómez (2010), quien concluyó que si bien el desempeño docente incide en ciertas características de los estudiantes, los resultados en sus calificaciones sólo lo hace en la motivación. Asimismo, Dolores y García (2016) afirmaron que el único objetivo de las evaluaciones es beneficiar los conocimientos y habilidades de los bachilleres. Mientras que Martínez y Camarena (2015) y la SEP (2019) plantean que el rendimiento académico desarrollará habilidades específicas circunscritas a operaciones numéricas, aplicación de los conocimientos en la vida práctica y al uso del lenguaje matemático, entre otros. Gaxiola et al. (2011), Mondragón, Cardoso y Bobadilla (2017) y Silas (2008) afirmaron que la resiliencia y la perseverancia pueden predecir el rendimiento académico de los estudiantes de bachillerato, pero no a la inversa, al igual que Robinsen et al. (2014) y Sierra (2016), quienes identificaron que el liderazgo de los docentes o de los padres de familia influye en las calificaciones de los jóvenes, pero no se encontró evidencia suficiente que indique asociación en sentido contrario a lo expuesto en la figura 2. Alonso et al. (2016) agregaron que si los resultados escolares coadyuvan a hacer frente a obstáculos, sucesos inesperados o cosas fuera de control entre los estudiantes, dicha contribución sería mínima, mientras que Aké et al. (2018) hacen referencia a que el rendimiento académico solo se asocia con las competencias conceptuales y técnicas. Mirete, Soro y Maquillón (2015) identificaron que el desinterés afectaba el rendimiento académico, pero no necesariamente el segundo afectaba al primero. Y Lara, González, González y Martínez (2014) agregaron el temor a afrontar diversos aspectos de la vida como elemento que afecta el rendimiento escolar pero tampoco encontró evidencia de que el segundo incidiera en el primero.

Cabe señalar que se revisaron algunas investigaciones que obtuvieron resultados diferentes a los aquí obtenidos: Salazar et al. (2018) ubicó que el rendimiento académico sí se asocia con la mejora en características personales, por ejemplo, el grado de aceptación y adaptación al entorno y sus niveles de autocontrol. Tuirán (2017) informó que en gran medida el rendimiento académico negativo incide en la disminución de la resiliencia, el desánimo, la 


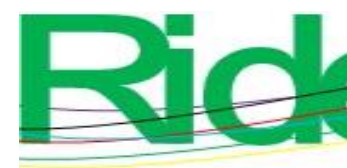

Revista Iberoamericana para la Investigación y el Desarrollo Educativo ISSN 2007 - 7467

pérdida de interés en las metas o en afrontar la vida, así como en la credibilidad de los profesores como líderes académicos. Finalmente, Corzo (2016) y Landero (2012) consideraron que el rendimiento académico negativo, además de generar temor para afrontar las cosas, contribuía a que los estudiantes fueran menos resilientes.

\section{Conclusiones}

El presente estudio logra el objetivo fijado. Los resultados muestran que el factor "Desempeño docente de matemáticas" y la variable "Rendimiento académico en matemáticas" se asocian con el factor "Aspectos positivos del estudiante".

Cuando los profesores de matemáticas emplean ejercicios y tareas que ayudan a memorizar conceptos y procedimientos, así como a aplicar los conocimientos adquiridos en clase a problemas o situaciones, aspectos positivos de los alumnos relacionadas con la perseverancia, como el interés y atención por metas y afrontar las cosas, la resiliencia ante obstáculos, sucesos inesperados y cosas fuera de control y el reconocimiento de la disciplina, concordar con los líderes o tener buena comunicación con los padres, por ejemplo, se incrementan.

En cuanto a las calificaciones en matemáticas, aunque hay correlación con "Aspectos positivos de los estudiantes", el impacto de la variable independiente en el constructo dependiente es prácticamente nulo, con una muy ligera tendencia negativa.

Algunas limitaciones del estudio fueron no haber tenido acceso previo al cuestionario de contexto para afinar los ítems relacionados con las variables aquí analizadas. Dentro de la interpretación de los resultados, uno de los retos fue comprender la relación entre dos constructos como el "Desempeño docente de matemáticas" y "Aspectos positivos de los estudiantes" cuando ambos conjugan, según la teoría analizada, una vasta cantidad de variables que aquí fue imposible abarcar. Una dificultad extra, que sin duda abrirá futuras líneas de investigación, es asociar el papel que juegan maestros de otras unidades de aprendizaje como español, ciencias naturales, ciencias sociales o incluso educación física con los aspectos positivos de los estudiantes.

Finalmente, algunas recomendaciones para favorecer el desempeño del profesorado de matemáticas, específicamente en relación a los ejercicios y tareas que emplean en sus clases, y que ayudarán a beneficiar los aspectos positivos de los estudiantes son: por supuesto, que las labores en el aula lleven al estudiante a la competencia numérica; emplear las 


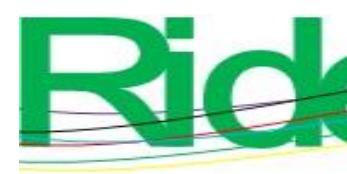

Revista Iberoamericana para la
Investigación y el Desarrollo Educativo
ISSN $2007-7467$

tecnologías de la información para aplicar actividades de manera virtual, dinámicas, atractivas, lúdicas e innovadoras que incluyan gráficos, modelos, simulaciones, demostraciones y prácticas reales, entre otros; aplicar actividades que potencialmente hayan sido experimentadas por los estudiantes en su vida real y que despierte en ellos el interés; desarrollar dinámicas cuyo objetivo sea el entendimiento de las matemáticas, más allá de la calificación, para que el resultado obtenido, en caso de que sea negativo, disuada la desmotivación de los estudiantes; propiciar la interacción asertiva docente-alumno en el transcurso de la clase, esto despierta tanto el afecto como el respeto hacia el maestro; propiciar que las evaluaciones de matemáticas generen información para la toma de decisiones tanto académicas como en materia de gestión de la clase y el establecimiento de tareas y ejercicios que lleven al cumplimiento de objetivos pedagógicos y de formación integral para la vida; aplicar quehaceres escolares que puedan ser elaborados entre profesores y alumnos y entre alumnos y sus familias; distribuir la ponderación de la calificación tanto en trabajos y exámenes como en participación, asistencia, colaboración grupal, interpretación de resultados, entre otros; compartir experiencias o lecturas sobre la importancia del saber matemático; inyectar un espíritu de reto en los alumnos cada vez que se planteen problemas o actividades de esta unidad de aprendizaje; promover la accesibilidad de los docentes, así como la disponibilidad incluso fuera de los horarios de clase; establecer planes de cátedra diaria que incluya la aplicación de ejercicios y tareas como laboratorios de problemas, casos prácticos y secuencias de resolución de problemas; emprender estrategias didácticas creativas que incluyan contextos reales, interacción, libre participación y objetivos alcanzables; concientizar a la comunidad estudiantil de que los errores pueden llevar a cosas buenas cuando se aprende de ellos y que el bachillerato es el espacio indicado para cometer fallas en los laboratorios de matemáticas sin grandes consecuencias para la vida; preguntar constantemente sobre dudas en clase; usar la cultura general y visiones globales y de futuro como herramientas para conectar con la enseñanza y el agrado por las matemáticas; fijar las metas del curso desde un inicio y ser ejemplo de comportamiento mediante la rectitud, puntualidad, amabilidad, diligencia, entre otros; capacitar a los docentes en lo referente a su materia para que sean considerados, por los alumnos, como los mejores, e iniciar con tareas y ejercicios matemáticos sencillos para después incrementar el grado de complejidad de conceptos, procedimientos y aplicación de conocimientos. 


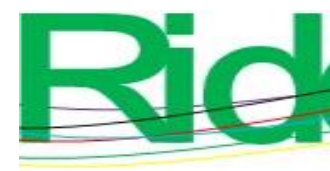

Revista Iberoamericana para la Investigación y el Desarrollo Educativo ISSN 2007 - 7467

\section{Futuras líneas de investigación}

A través de la revisión de la literatura que se realizó en el presente artículo, se identificaron diversos factores que se pudieran asociar con aspectos positivos del estudiante, los cuales, por razones de tiempo y recursos, fue imposible abordar en la presente propuesta.

Así, será interesante estudiar el grado en el que el desempeño de los docentes de español e inglés, particularmente, inciden en el constructo dependiente aquí propuesto. Igualmente, cuál es el grado en que factores como maestros facilitadores, la convivencia escolar y los padres supervisores determinan los aspectos positivos del estudiante, específicamente en bachilleratos militarizados. Por otro lado, para futuros estudios se pretende determinar el nivel en que los aspectos positivos del estudiante pudieran relacionarse con dos temas de profundo interés para los científicos de la educación: la reprobación y la permanencia escolar en el nivel medio superior.

Por último, se propondrán proyectos donde se estudien los constructos aquí analizados, pero en contextos diferentes a subsistemas militarizados, como los autónomos, estatales o federales, particularmente en el estado de Nuevo León.

\section{Referencias}

Aké, L., Martínez, C. y López, J. (2018). Didáctica de la matemática: una reflexión sobre su interpretación en el contexto escolar. En Salazar, M., Peña, C. y Medina, R. (comp. ${ }^{\text {as}), ~}$ Estrategias de enseñanza y aprendizaje para la docencia universitaria. Experiencias desde el aula (pp. 127-140). Colima, México: Universidad de Colima.

Alonso, R., Beltrán, Y., Méfara, R. y Gaytán, Z. (2016). Relación entre rendimiento académico y resiliencia en una Universidad Tecnológica. Revista de Investigaciones Sociales, 2(4), 38-49.

Álvarez, J., Torres, A. y Chaparro, E. (2016). Diagnóstico del liderazgo educativo en las instituciones de educación superior del Valle de Toluca. Revista de Investigación Educativa, 34(1), 51-68. Recuperado de http://dx.doi.org/10.6018/rie.34.1.206881.

Arguedas, I. y Jiménez, F. (2007). Factores que promueven la permanencia de estudiantes en la educación secundaria. Actualidades Investigativas en Educación, 7(3), 1-36. Recuperado de http://redalyc.org/articulo.oa?id=44770317. 


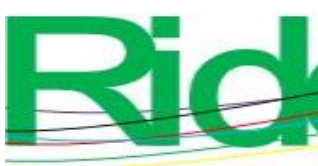

Revista Iberoamericana para la Investigación y el Desarrollo Educativo

ISSN 2007 - 7467

Artavia, J. (2005). Interacciones personales entre docentes y estudiantes en el proceso de enseñanza y aprendizaje. Actualidades Investigativas en Educación, 5(2). 1-19. Recuperado de http://www.redalyc.org/articulo.oa?id=44750208.

Barragán, A., Aguilar, M., Cerpa, G. y Núñez, H. (2009). Relaciones docente-alumno y rendimiento académico. Un caso del Centro Universitario de Ciencias Exactas e Ingenierías de la Universidad de Guadalajara. Sinéctica, (33), 1-15. Recuperado de http://www.scielo.org.mx/scielo.php?script=sci_arttext\&pid=S1665109X2009000200006.

Barrales, A., Gómez, A. y Guerrero, L. (2015). Factores que originan la reprobación en los estudiantes de bachillerato: caso Colegio Motolinía. En Hernanz, J. A. y Watty, M. (coords.), Tendencias y desafios en la innovación educativa: un debate abierto (pp. 881-890). Xalapa, México: Fundación para la Educación Superior Internacional. Recuperado de https://www.repo-ciie.dfie.ipn.mx/pdf/452.pdf.

Barraza, A. y Silerio, J. (2007). El estrés académico en el alumno de educación media superior: un estudio comparativo. Investigación Educativa Duranguense, (7), 48-65. Recuperado de https://dialnet.unirioja.es/servlet/articulo?codigo=2358918.

Basto, R. (2017). La función docente y el rendimiento académico: una aportación al estado de conocimiento. Ponencia presentada en el XIV Congreso Nacional de Investigación Educativa. San Luis Potosí, 2017. Recuperado de https://www.comie.org.mx/congreso/memoriaelectronica/v14/doc/2030.pdf.

Becerra, C. y Reidl, L. (2015). Motivación, autoeficacia, estilo atribucional y rendimiento escolar de estudiantes de bachillerato. Revista Electrónica de Investigación Educativa, 17(3), 79-93. Recuperado de http://redie.uabc.mx/vol17no3/contenidobecerra-reidl.html.

Beresaluce, R., Peiró, S. y Ramos, C. (2014) El profesor como guía orientador. Un modelo docente. Ponencia presentada en las XII Jornadas de Redes de Investigación en Docencia Universitaria. España. Recuperado de http://hdl.handle.net/10045/41885.

Barojas, J. y Ramírez, G. (2015). Estrategias de aprendizaje para estudiantes con graves deficiencias al ingresar al bachillerato. Perfiles Educativos, 37(especial), 69-88. Recuperado de http://www.scielo.org.mx/scielo.php?script=sci_arttext\&pid=S018526982015000500006.

Camberos, D., Lechuga, M. y Salinas, P. (2014). Diseño de estrategias de aprendizaje creativas en la enseñanza del idioma inglés en estudiantes de bachillerato en $\mathrm{Cd}$. 


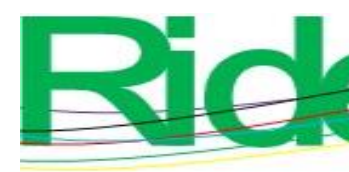

Revista Iberoamericana para la
Investigación y el Desarrollo Educativo
ISSN $2007-7467$

Juárez, Chihuahua. Revista de Investigación Educativa de la Escuela de Graduados en Educación, 4(8), 10-15. Recuperado de https://rieege.mx/index.php/rieege/article/view/82.

Campos, M., Castaño, W. y Valencia, M. (2013), El proceso de adaptación escolar y el desempeño académico como apuesta para la calidad educativa. Recuperado de http://ridum.umanizales.edu.co:8080/xmlui/handle/6789/695.

Campuzano, M. y Libien, Y. (2019). Resiliencia en estudiantes como herramienta para asegurar la calidad educativa. Revista Electrónica sobre Educación Media y Superior, 6(11), 1-15. Recuperado de https://www.cemys.org.mx/index.php/CEMYS/article/view/285/317.

Carlos, J. (2016). ¿Qué y cómo evaluar el desempeño docente? Una propuesta basada en los factores que favorecen el aprendizaje. Propósitos y Representaciones, 4(2), 285-358. Recuperado de http://dx.doi.org/10.20511/pyr2016.v4n2.124.

Castro, M. y Morales, M. (2015). Los ambientes de aula que promueven el aprendizaje desde la perspectiva de los niños y niñas escolares. Revista Electrónica Educare, 19(3), 132. Recuperado de http://dx.doi.org/10.15359/ree.19-3.11.

Cerda, G., Salazar, Y., Guzmán, C. y Narváez, G. (2018). Impacto de la convivencia escolar sobre el rendimiento académico desde la percepción de estudiantes con desarrollo típico y necesidades educativas especiales. Propósitos y Representaciones, 6(1), 247300. Recuperado de http://dx.doi.org/10.20511/pyr2018.v6n1.194.

Chávez, M. (2014). Propuestas para superar los principales problemas educativos que enfrenta el nivel medio superior. Presencia Universitaria, 4(8), 48-57. Recuperado de http://eprints.uanl.mx/7446/.

Chilca, M. (2017). Autoestima, hábitos de estudio y rendimiento académico en estudiantes universitarios. Propósitos y Representaciones, 5(1), 71-127. Recuperado de http//dx.doi.org/10.20511/pyr2017.v5n1.145.

Colegio de Bachilleres Militarizado General Mariano Escobedo del Estado de Nuevo León (CBMNL). (2019). Plan de Desarrollo Institucional 2019-2024. México: Colegio de Bachilleres Militarizado General Mariano Escobedo del Estado de Nuevo León.

Grupo de trabajo "Investigación sobre el abandono escolar temprano". (2013). Abandono escolar temprano. Factores de abandono y factores de continuidad. Intervenciones posibles desde los centros educativos. España: Junta de Castilla y León-Consejería 


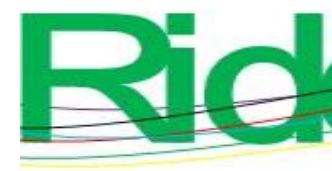

Revista Iberoamericana para la Investigación y el Desarrollo Educativo ISSN $2007-7467$

de Educación. Recuperado de www.educa.jayl.es/crol/es/capacitaciondocente/abandono-escolar-temprano-factores-abandono-factores-contin.

Consejo Nuevo León para la Planeación Estratégica [CONL]. (2020a). ¿Quiénes somos? Recuperado de https://www.conl.mx/quienes_somos.

Consejo Nuevo León para la Planeación Estratégica [CONL]. (2020b). Evaluación Integral de los Planteles del Colegio de Bachilleres Militarizado de Nuevo León. México: Subcomisión de Desarrollo Humano del Consejo Nuevo León para la Planeación Estratégica.

Corzo, C. (2016). Deserción escolar. Con-Ciencia, 4(8). Recuperado de http://repository.uach.edu.mx/revistas/index.php/prepa3/article/view/2568.

Covarrubias, P. y Piña, M. (2004). La interacción maestro-alumno y su relación con el aprendizaje. Revista Latinoamericana de Estudios Educativos, 34(1), 47-84. Recuperado de https://www.redalyc.org/pdf/270/27034103.pdf.

Dzay, F. y Narváez, Ó. (2012). La deserción escolar desde la perspectiva estudiantil. Ciudad de México, México: Universidad de Quintana Roo.

Dolores, C. y García, J. (2016). Concepciones de profesores de matemáticas sobre la evaluación y las competencias. Números. Revista de Didáctica de las Matemáticas. 92, 71-92. Recuperado de sinewton.org/numeros/numeros/92/Articulos_06.pdf.

Domínguez, H., Gutiérrez, J., Llontop, M., Villalobos, D. y Delva, J. (2015). Estilos de aprendizaje: un estudio diagnóstico en el Centro Universitario de Ciencias Económico-Administrativas de la U. de G. Revista de Educación Superior, 44(175), 121-140. Recuperado de http://www.scielo.org.mx/scielo.php?pid=S018527602015000300006\&script=sci_abstract.

El Sahili, L. (2011). Informe de investigación sobre deserción escolar mediante jerarquización de factores en la UPIIG del IPN en Silao, Guanajuato. REXE. Revista de Estudios y Experiencias en Educación, 10(19), 33-48. Recuperado de https://www.redalyc.org/pdf/2431/243120126002.pdf.

Encinas, F., Peralta, J., Cuevas, O. y Anseldo, J. (2017). Diagnóstico de los conocimientos básicos de matemáticas en alumnos universitarios de nuevo ingreso. Revista de Docencia e Investigación Educativa, 3(7), 1-13. Recuperado de https://dialnet.unirioja.es/servlet/articulo?codigo=7473314. 


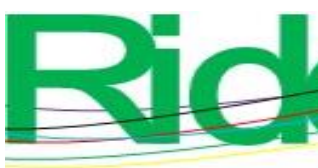

Revista Iberoamericana para la Investigación y el Desarrollo Educativo ISSN 2007 - 7467

Escobar, M. (2015). Influencia de la interacción alumno-docente en el proceso de enseñanzaaprendizaje. Paakat: Revista de Tecnología y Sociedad, 5(8), 1-9. Recuperado de http://www.redalyc.org/articulo.oa?id=499051499006.

Fernández, J. (2014). Resiliencia una alternativa en educación media. Revista Iberoamericana de Producción Académica y Gestión Educativa, 1(1), 1-19. Recuperado de https://www.pag.org.mx/index.php/PAG/article/view/110.

Flores, A. y Gómez, A. (2009). Aprender matemática, haciendo matemática: la evaluación en el aula. Educación Matemática, 21(2), 117-142. Recuperado de http://www.scielo.org.mx/pdf/ed/v21n2/v21n2a5.pdf.

García, B. (2009). Las dimensiones afectivas de la docencia. Revista Digital Universitaria, 10(11), 1-14. Recuperado de http://www.revista.unam.mx/vol.10/num11/art71/art71.pdf.

García, B. y Klein, I. (2014). La construcción de ambientes educativos para la convivencia pacífica: el modelo pedagógico del programa SaludARTE. Sinéctica, (42), 1-13. Recuperado de http://www.scielo.org.mx/scielo.php?script=sci_arttext\&pid=S1665109X2014000100006.

Gaxiola, J., González, S. y Contreras, Z. (2011). Influencia de la resiliencia, metas y contexto social en el rendimiento académico de bachilleres. Revista Electrónica de Investigación Educativa, 14(1), 164-181. Recuperado de http://www.scielo.org.mx/scielo.php?script=sci_arttext\&pid=S160740412012000100011.

George, D. and Mallery, P. (2003). SPSS for Windows Step by Step: A Simple Guide and Reference ( th $^{\text {th }}$ ed.). Boston, United States: Allyn \& Bacon.

Gobierno del Estado de Nuevo León. (2019). Cuarto Informe de Gobierno|Administración 2015-2021. México: Gobierno del Estado de Nuevo León. Recuperado de https://www.nl.gob.mx/publicaciones/cuarto-informe-de-gobierno-administracion2015-2021.

Gómez, M. y Vázquez. E. (2014). Deserción a nivel medio superior en escuela superior Tepeji. Tepexi. Boletín Científico de la Escuela Superior Tepeji, 1(2), 1-5. Recuperado de https://www.uaeh.edu.mx/scige/boletin/tepeji/n2/e3.html.

Gómez, I. (2010). Actitudes de los estudiantes en el aprendizaje de la matemática con tecnología. Enseñanza de la Ciencias, 28(2). 227-244. Recuperado de https://raco.cat/index.php/Ensenanza/article/view/199615. 


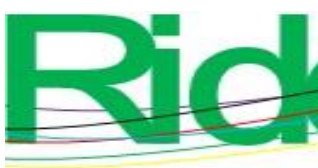

Revista Iberoamericana para la Investigación y el Desarrollo Educativo

ISSN $2007-7467$

González, M. y Treviño, D. (2018). Logro educativo y factores asociados en estudiantes de sexto grado de educación primaria en el estado de Nuevo León, México. Perfiles Educativos, 11(159), 107-125. Recuperado de http://www.scielo.org.mx/pdf/peredu/v40n159/0185-2698-peredu-40-159-107.pdf.

Hernández, J. y Backhoff, E. (2017). Evaluación del aprendizaje en la educación media superior. Gaceta de la Política Nacional de Evaluación Educativa en México, 3(7), 23-27. Recuperado de https://www.inee.edu.mx/wp-content/uploads/2018/12/G07esp.pdf.

Hernández, J., Rivera, M. y Garza, L. (2017). Ambientes de aprendizaje en el bachillerato. Ponencia presentada en el XIV Congreso Nacional de Investigación Educativa. San Luis Potosí, del 20 al 24 de noviembre de 2017.

Hernández, L. y Ceniceros, D. (2018). Autoeficacia docente y desempeño docente, ¿una relación entre variables? Innovación Educativa, 18(78), 171-192. Recuperado de http://www.scielo.org.mx/scielo.php?script=sci_abstract\&pid=S1665$26732018000300171 \& \operatorname{lng}=\mathrm{es} \& n r m=\mathrm{i}$.

Instituto Nacional para la Evaluación de la Educación [INEE]. (2017). Planea. Resultados Nacionales 2017. México: Instituto Nacional para la Evaluación de la Educación.

Islas, C. y Carranza, M. (2011). Uso de las redes sociales como estrategias de aprendizaje, ¿transformación educativa? Apertura. Revista de Innovación Educativa, 3(2). Recuperado de udgvirtual.udg.mx/apertura/index.php/apertura/article/view/198/213.

Jaik, A. y Barraza, A. (coords.) (2011). Competencias y Educación. Miradas Múltiples de una Relación. México: Instituto Universitario Anglo Español-Red Durango de Investigadores Educativos.

Lagos, N. y Osse, C. (2010). Representaciones acerca de la resiliencia en educación según la opinión de los actores de la comunidad educativa. Horizontes Educacionales, 15(1), 37-52. Recuperado de https://www.redalyc.org/articulo.oa?id=97916218004.

Landero, J. (2012). Deserción en la educación media superior en México. (Proyecto de investigación aplicada). Tecnológico de Monterrey, Ciudad de México.

Lara, A., Aguilar, M., Cerpa, G. y Núñez, H. (2009). Relaciones docente-alumno y rendimiento académico. Un caso del Centro Universitario de Ciencias Exactas e Ingenierías de la Universidad de Guadalajara. Sinéctica, (33), 1-15. Recuperado de http://www.scielo.org.mx/scielo.php?script=sci_arttext\&pid=S1665109X2009000200006. 


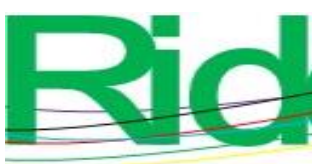

Revista lberoamericana para la Investigación y el Desarrollo Educativo

ISSN 2007 - 7467

Lara, B., González, A., González, M. y Martínez, M. (2014). Fracaso escolar: conceptualización y perspectivas de estudio. Revista de Educación y Desarrollo, (30), 71-83. Recuperado de http://www.cucostasur.udg.mx/sites/default/files/30_lara.pdf.

López, A., García, M. y Díaz, A. (2018). Hábitos de estudio y fracaso escolar en educación media superior. Praxis Investigativa ReDIE, 10(19), 84-104. Recuperado de https://dialnet.unirioja.es/servlet/articulo?codigo $=6571560$.

Lugo, B. (2013). La deserción estudiantil: ¿realmente es un problema social? ARJE. Revista de Posgrado FACE-UC, 7(12), 289-309. Recuperado de http://www.arje.bc.uc.edu.ve /arj12/art17.pdf.

Martínez, C. (2018). La formación de profesores de matemáticas. En Salazar, M., Peña, C. y Medina, R. (comp. ${ }^{\text {as }}$ ), Estrategias de enseñanza y aprendizaje para la docencia universitaria. Experiencias desde el aula (pp. 114-126). Colima, México: Universidad de Colima.

Martínez, M., Soberanes, A. y Sánchez, J. (2017). Análisis correlacional de competencias matemáticas de pruebas estandarizadas y prerrequisitos matemáticos en estudiantes de nuevo ingreso a ingeniería en Computación. Revista Iberoamericana para la Investigación y el Desarrollo Educativo, 8(15), 1-29. Recuperado de https://www.ride.org.mx/index.php/RIDE/article/view/328.

Martínez, X. y Camarena, P. (coords.) (2015). La evaluación matemática en el siglo XXI. Ciudad de México, México: Instituto Politécnico Nacional.

Martínez, G., Guevara, A. y Valles, M. (2016). El desempeño docente y la calidad educativa. Ra Ximhail. 12(2). 123-134. Recuperado de https://www.redalyc.org/pdf/461/46148194007.pdf.

Martínez-Otero, V. (2009). Investigación y reflexión sobre condicionantes del fracaso escolar. Revista Latinoamericana de Estudios Educativos, 39(1-2), 11-38. Recuperado de https://www.redalyc.org/pdf/270/27015065002.pdf.

Mesa, L., Marcos, P. y Vidales, M. (2017). Características de docentes líderes de proyectos pedagógicos que contribuyen al mejoramiento de los estudiantes. Revista de Investigación Educativa de la Escuela de Graduados en Educación, 8(15), 58-63. Recuperado de http://rieege.tecvirtual.mx/index.php/rieege/article/view/355.

Mirete, A., Soro, M. y Maquillón, J. (2015). El fracaso escolar y los enroques de aprendizaje: medidas para la inclusión educativa. Revista Electrónica Interuniversitaria de 


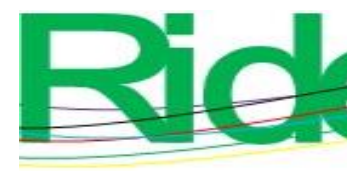

Revista Iberoamericana para la Investigación y el Desarrollo Educativo

ISSN 2007 - 7467

Formación del Profesorado, 18(3), 183-196. Recuperado de https://doi.org/10.6018/ reifop.18.3.239021.

Mondragón, C., Cardoso, D. y Bobadilla, S. (2017). Hábitos de estudio y rendimiento académico. Caso estudiantes de la licenciatura en administración de la unidad académica profesional. Tejupilco, 2016. Revista Iberoamericana para la Investigación y el Desarrollo Educativo, 8(15), 1-25. Recuperado de https://www.ride.org.mx/index.php/RIDE/article/view/315.

Morales, H. (2017). Decálogo de principios pedagógicos esenciales para la docencia frente a los jóvenes. Gaceta de la Política Nacional de Evaluación Educativa en México, 3(7), 34-43. Recuperado de https://www.inee.edu.mx/wp-content/uploads/2018/12/G07esp.pdf.

Morales, S. (2018). La evaluación del desempeño docente como insumo para el mejoramiento del proceso de enseñanza aprendizaje en la Universidad Autónoma Juan Misael Saracho. Investigación y Negocios, 11(18), 72-85. Recuperado de http://www.scielo.org.bo/scielo.php?script=sci_abstract\&pid=S2521$27372018000200008 \& \operatorname{lng}=$ es\&nrm=iso.

Monroy, L., Jiménez, V., Ortega, L. y Chávez, M. (2013). ¿Quiénes son los estudiantes que abandonan los estudios? Identificación de factores personales y familiares asociados al abandono escolar en estudiantes de educación media superior. Ponencia presentada en el 3. ${ }^{a}$ Conferencia sobre el Abandono en la Educación Superior. Ciudad de México, del 13 al 15 de noviembre de 2013.

Montes, N. y Machado, E. (2011). Estrategias docentes y métodos de enseñanza-aprendizaje en la Educación Superior. Humanidades Médicas, 11(3), 1-11. Recuperado de http://scielo.sld.cu/scielo.php?script=sci_arttext\&pid=S1727-81202011000300005.

Muñiz, C., Maldonado, L., Leyva, O., López, R., Saldierna, A., Hernández, T. y Rodríguez, E. (2011). Hábitos comunicativos y sofisticación política. En Muñiz, C. (coord.), Comunicación, Política y Ciudadanía, (pp. 237-253). Ciudad de México, México: Fontamara.

Ortega, P., Macías, M. y Hernández, M. (2014). Causas de la deserción escolar en las telesecundarias de la zona 55. Huella de la Palabra, (8), 31-54. Recuperado de https://revistas.lasallep.edu.mx/index.php/huella/article/view/491.

Padilla, B. y Villafuerte, A. (2018). Desempeño docente y rendimiento académico de los estudiantes del curso de técnicas de estudio de una universidad privada confesional. 


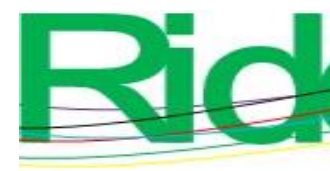

Revista Iberoamericana para la Investigación y el Desarrollo Educativo ISSN 2007 - 7467

Muro de la Investigación, 3(1), 13-30. Recuperado de https://revistas.upeu.edu.pe/index.php/r-Muro-investigaion/article/view/1111.

Peña, C., Andrade, A. y Aké L. (2018). El practicum en la licenciatura en enseñanza de las matemáticas: eje transversal de integración de competencias genéricas y profesionales. 97-112. En Salazar, M., Peña, C. y Medina, R. (comp. ${ }^{\text {as }}$ ), Estrategias de enseñanza y aprendizaje para la docencia universitaria. Experiencias desde el aula. Colima, México: Universidad de Colima.

Peña, M. y Vera, J. (2014). La comprensión lectora en los egresados de Educación Media Superior en Sonora. En Vázquez, M., Zavala, M., González, I. y Rodríguez, A. (eds.), Investigaciones y aportaciones para la innovación educativa en Sonora. Ideas, procesos y estrategias para la transferencia de conocimiento (pp. 247-275). México: ITSON-Tabook.

Poy, R. (2010). Efectos del credencialismo y las expectativas sociales sobre el abandono escolar. Revista de Educación, (número extraordinario), 147-169.

Reyes, V., Trejo, M. y Topete, C. (2017). El liderazgo directivo y la gestión en el nivel medio superior del Instituto Politécnico Nacional de México: una mirada desde los estudiantes. Revista Iberoamericana para la Investigación y el Desarrollo Educativo, 8(15), 1-35. Recuperado de https://doi.org/10.23913/ride.v8i15.292.

Ricoy, M. y Cauto, M. (2018). Desmotivación del alumnado de secundaria en la materia de matemáticas. Revista Electrónica de Investigación Educativa, 20(3), 69-79. Recuperado de http://doi.org/10.24320/redie.2018.20.3.1650.

Rivera, L., Figueroa, S. y Edel, R. (2013). Competencias docentes: un reto para el nivel medio superior de México. Ponencia presentada en el 1. ${ }^{\text {er }}$ Congreso Internacional de Transformación Educativa. Ixtapan de la Sal, del 3 al 5 de octubre de 2013.

Robinsen, V., Lloyd, C. y Rowe, K. (2014). El impacto del liderazgo en los resultados de los estudiantes: un análisis de los efectos diferenciales de los tipos de liderazgo. REICE. Revista Iberoamericana sobre la Calidad, Eficacia y Cambio en Educación, 12(4e), 13-40. Recuperado de https://revistas.uam.es/reice/article/view/2835/3052.

Rodríguez, J. (2011). Estrategias de enseñanza utilizadas por los docentes en la educación media superior. Ponencia presentada en el IX Congreso Nacional de Investigación Educativa. Ciudad de México, del 7 al 11 de noviembre. Recuperado de http://www.comie.org.mx/congreso/memoriaelectronica/v11/docs/area_15/2405.pdf 


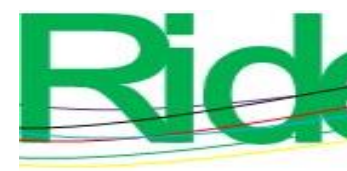

Revista Iberoamericana para la Investigación y el Desarrollo Educativo

ISSN $2007-7467$

Roux, R. y Anzures, E. (2015). Estrategias de aprendizaje y su relación con el rendimiento académico en estudiantes de escuela privada de educación media superior. Revista Electrónica Actualidades Investigativas en Educación, 15(1), 1-16. Recuperado de https://revistas.ucr.ac.cr/index.php/aie/article/view/17731.

Ruiz, P. (2013). Los problemas escolares en la adolescencia. Pediatría Integral, 17(2), 117127.

Salazar, M., Peña, C. y Medina, R. (comp. ${ }^{\text {as }}$ ). (2018). Estrategias de enseñanza y aprendizaje para la docencia universitaria. Experiencias desde el aula. Colima, México: Universidad de Colima. Recuperado de http://ww.ucol.mx/content/publicacionesenlinea/adjuntos/Estrategias-deensenianza-y-aprendizaje-para-la-docencia-universitaria_473.pdf.

Salvà, F., Oliver, M. y Comas, R. (2014). Abandono escolar y desvinculación de la escuela: perspectiva del alumnado. Revista Internacional de Investigación en Educación, 6(13), 129-142.

Sánchez, M., Téllez, M., Sánchez, J. y Reyes V. (2017). Conceptualizando las necesidades de actualización y profesionalización docente en el nivel medio superior. Revista Dilemas Contemporáneos, 4(3). 1-33. Recuperado de https://www.dilemascontemporaneoseducacionpoliticayvalores.com/index.php/dile mas/article/view/189.

Santana, R., Marchena, R., Martín, J. y Alemán, J. (2018). Abandono escolar y formación docente: interpretaciones del profesorado de educación secundaria. Aula Abierta, 47(3), 365-372. Recuperado de https://dialnet.unirioja.es/servlet/articulo?codigo $=6723288$.

Santiago, P., McGregor, I., Nusche, D., Ravelo, P. y Toledo, D. (2012). Revisión de la OCDE sobre la evaluación en educación. México. México: Organización para la Cooperación y el Desarrollo Económicos.

Saucedo, M., Herrera, S., Díaz, J., Bautista, S. y Salinas, H. (2014). Indicadores de reprobación: Facultad de Ciencias Educativas. Revista Iberoamericana para la Investigación y el Desarrollo Educativo, 5(9), 1-12. Recuperado de https://www.redalyc.org/pdf/4981/498150317007.pdf.

Secretaría de Educación Pública [SEP] (2015). Guía para la elaboración de expediente de evidencias de enseñanza. México: Secretaría de Educación Pública. 


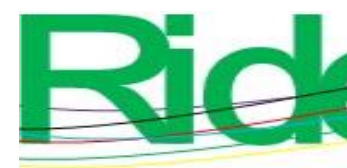

\section{Revista Iberoamericana para la Investigación y el Desarrollo Educativo ISSN 2007 - 7467}

Secretaría de Educación Pública [SEP]. (2017). Examen Planea 2017 Media Superior. México: Secretaría de Educación Pública.

Secretaría de Educación Pública [SEP]. (26 de septiembre de 2018). Acuerdo 442 por el que se establece el Sistema Nacional de Bachillerato en un marco de diversidad. Diario Oficial de la Federación. http://dof.gob.mx/nota_detalle.php?codigo=5061936\&fecha=26/09/2008.

Secretaría de Educación Pública [SEP]. (29 de octubre de 2018). Acuerdo 447 por el que se establecen las competencias docentes para quienes imparten educación media superior en la modalidad escolarizada. Diario Oficial de la Federación. Recuperado de http://dof.gob.mx/nota_detalle.php?codigo=5066425\&fecha=29/10/2008.

Secretaría de Educación Pública [SEP]. (2019). Evaluación diagnóstica al ingresar a la educación media superior. Manual del alumno de la competencia matemática. México: Secretaría de Educación Pública.

Sesento, L. y Lucio, R. (2017). Métodos de estudio, los estilos de aprendizaje en educación media superior. Revista de Pedagogía Crítica. 1(2). 31-37. Recuperado de https://www.ecorfan.org/republicofperu/research_journals/Revista_de_Pedagogia_C ritica/vol1num2/Revista_de_Pedagog\%C3\%ADa_Cr\%C3\%ADtica_V1_N2_4.pdf.

Sierra, G. (2016). Liderazgo educativo en el siglo XXI desde la perspectiva del emprendimiento sustentable. Revista de la Escuela de Administración y Negocios, (81). 111-128.

Recuperado

de https://www.redalyc.org/journal/206/20649705007/html/.

Silas, J. C. (2008). La resiliencia en los estudiantes de educación básica, un tema primordial en comunidades marginales. Sinéctica, (31), 1-32. Recuperado de https://www.redalyc.org/articulo.oa?id=99812248002.

Smitter, Y. (2008). Lineamientos para la autoevaluación del desempeño docente en las funciones de docencia, investigación y extensión en el Instituto Pedagógico de Miranda "José Manuelsiso Martínez". Investigación y Postgrado, 23(3), 1-6. Recuperado de http://ve.scielo.org/scielo.php?pid=S131600872008000300013\&script=sci_abstract.

Smulders, M. (2018). Factores que influyen en la deserción de los estudiantes universitarios. Academo. Revista de Investigación en Ciencias Sociales y Humanidades, 5(2), $127-$ 132. Recuperado de http://scielo.iics.una.py/pdf/academo/v5n2/2414-8938academo-5-02-127.pdf. 


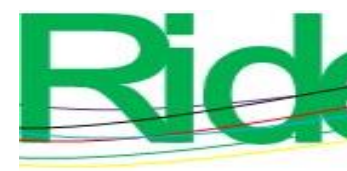

\section{Revista Iberoamericana para la Investigación y el Desarrollo Educativo ISSN 2007 - 7467}

Tapia, M., Tamez, A. y Tovar, A. (1994). Causas de reprobación en los Colegios de Bachilleres del Estado de Morelos. Revista Latinoamericana de Estudios Educativos, 24(1-2), 107-128.

Tello, J. y Tello, L. (2013). Percepción de los estudiantes del desempeño docente en la región Junín. Horizonte de la Ciencia, 3(4). 89-96. Recuperado de https://docplayer.es/67326668-Percepcion-de-los-estudiantes-del-desempenodocente-en-la-region-junin.html.

Tuirán, R. (2017). La educación media superior como cimiento de un proyecto de vida. Gaceta de la Política Nacional de Evaluación Educativa en México, 3(7), 12-15. Recuperado de https://www.inee.edu.mx/wp-content/uploads/2018/12/G07-esp.pdf.

Tuirán, R. y Hernández, D. (1 de noviembre de 2015). La evaluación de los aprendizajes en Educación Media Superior. Revista Este País. Recuperado de https://anterior.estepais.com/articulo.php?id=311\&t=la-evaluacion-de-losaprendizajes-en-la-educacion-media-superior.

Velázquez, Y. y González, M. (2017). Factores asociados a la permanencia de estudiantes universitarios: Caso UAMM-UAT. Revista de Educación Superior, 46(184), $117-$ 138. Recuperado de https://doi.org/10.1016/j.resu.2017.11.003.

Venet, R. y Díaz, E. (2018). La formación emocional del docente. Una consideración necesaria para su profesionalización. Revista Dilemas Contemporáneos, 6(13), 1-28. Recuperado de

https://www.dilemas contemporaneoseducacionpoliticayvalores.com/index.php/dilemas/article/view/629.

Vidal, D. y Márquez, L. (2016). El docente como mediador de la comprensión lectora en universitarios. Revista de Educación Superior, 45(177), 95-118. Recuperado de http://resu.anuies.mx/ojs/index.php/resu/article/view/137.

Vidales, S. (2009). El fracaso escolar en la educación media superior: El caso del bachillerato de la Universidad Mexicana. Revista Iberoamericana sobre Calidad, Eficiencia y Cambio en Educación, 7(4), 320-341. Recuperado de https://revistas.uam.es /reice/article/view/5395.

Welch, S. and Comer, J. (1988). Quantitative Methods for Public Administration: Techniques and Applications. United States: Dorsey Press.

Zapata, F. (2017). Yo, tú, él, nosotros, vosotros y ellos. El rol del docente como articulador del clima áulico. Escritos en la Facultad, 13(136), 88-89. 


\begin{tabular}{|c|c|}
\hline Rol de Contribución & Autor (es) \\
\hline Conceptualización & $\begin{array}{l}\text { David Fernando Lozano Treviño (principal) y Lauro } \\
\text { Maldonado Maldonado (que apoya) }\end{array}$ \\
\hline Metodología & $\begin{array}{l}\text { David Fernando Lozano Treviño (principal) y Lauro } \\
\text { Maldonado Maldonado (que apoya) }\end{array}$ \\
\hline Software & Lauro Maldonado Maldonado \\
\hline Validación & $\begin{array}{l}\text { David Fernando Lozano Treviño (principal) y Lauro } \\
\text { Maldonado Maldonado (de apoyo) }\end{array}$ \\
\hline Análisis Formal & $\begin{array}{l}\text { David Fernando Lozano Treviño (principal) y Lauro } \\
\text { Maldonado Maldonado (de apoyo) }\end{array}$ \\
\hline Investigación & David Fernando Lozano Treviño \\
\hline Recursos & $\begin{array}{l}\text { David Fernando Lozano Treviño (Con apoyo de la Universidad } \\
\text { Autónoma de Nuevo León) }\end{array}$ \\
\hline Curación de datos & David Fernando Lozano Treviño \\
\hline $\begin{array}{l}\text { Escritura - Preparación del } \\
\text { borrador original }\end{array}$ & David Fernando Lozano Treviño \\
\hline $\begin{array}{l}\text { Escritura - Revisión y } \\
\text { edición }\end{array}$ & $\begin{array}{l}\text { David Fernando Lozano Treviño (principal) y Lauro } \\
\text { Maldonado Maldonado (de apoyo) }\end{array}$ \\
\hline Visualización & $\begin{array}{l}\text { David Fernando Lozano Treviño (principal) y Lauro } \\
\text { Maldonado Maldonado (de apoyo) }\end{array}$ \\
\hline Supervisión & David Fernando Lozano Treviño \\
\hline Administración de Proyectos & David Fernando Lozano Treviño \\
\hline Adquisición de fondos & $\begin{array}{l}\text { David Fernando Lozano Treviño (principal) y Lauro } \\
\text { Maldonado Maldonado (de apoyo) }\end{array}$ \\
\hline
\end{tabular}

